\title{
2010/18
}

Bank secrecy, illicit money and offshore financial centers

Pierre M. Picard and Patrice Pieretti

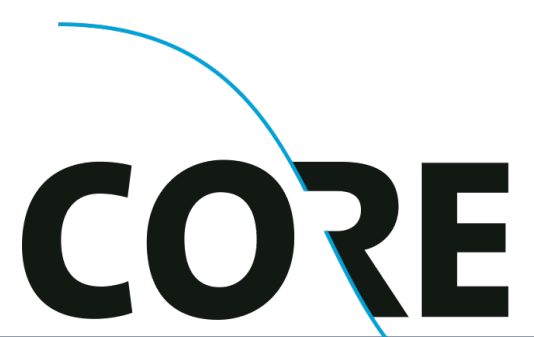

DISCUSSION PAPER

Center for Operations Research and Econometrics

Voie du Roman Pays, 34 B-1348 Louvain-la-Neuve Belgium http://www.uclouvain.be/core 


\title{
CORE DISCUSSION PAPER
}

$2010 / 18$

\section{Bank secrecy, illicit money and offshore financial centers}

\author{
Pierre M. PICARD ${ }^{1}$ and Patrice PIERETTI ${ }^{2}$
}

May 2010

\begin{abstract}
This paper discusses the effects of pressure policies on offshore financial centers as well as their ability to enforce the compliance of those centers with anti-money laundering regulations. Offshore banks can be encouraged to comply with rigorous monitoring of an investor's identity and the origin of his/her funds when pressure creates a sufficiently high risk of reputational harm to the investor. We show that such pressure policies harm both offshore and onshore investors and can benefit both the bank industry and tax administrations. We show that social optimal pressure policies are dichotomous decisions between no pressure at all and a pressure great enough to persuade offshore banks to comply. The delegation of pressure policies to onshore tax institutions may be inefficient. Deeper financial integration fosters compliance by the offshore center.
\end{abstract}

Keywords: money laundering, offshore banking, compliance.

JEL Classification: F21, K42

\footnotetext{
${ }^{1}$ Université du Luxembourg, CREA, L-1511 Luxembourg; Université catholique de Louvain, CORE, B-1348 Louvain-la-Neuve, Belgium. E-mail: Pierre.picard@uni.lu

${ }^{2}$ Université du Luxembourg, CREA, L-1511 Luxembourg. E-mail: Patrice.pieretti@uni.lu

We are grateful to the editor and two referees for their useful comments.

This paper presents research results of the Belgian Program on Interuniversity Poles of Attraction initiated by the Belgian State, Prime Minister's Office, Science Policy Programming. The scientific responsibility is assumed by the authors.
} 


\section{Introduction}

Offshore financial centers are often viewed as parasites that thrive by attracting tax cheaters and money-launderers. ${ }^{12}$ However, sovereignty and democratic independence limit the ability of international bodies to intervene directly in the private economy of offshore financial centers. As noted by Abbott and Snidal (2000), "diminution of sovereignty makes states reluctant to accept hard legalization, especially when it includes significant levels of delegation". This difficulty is emphasized by the fact that bank secrecy represents an important asset of offshore financial centers. However, since the early 1990s, there have been multilateral efforts to address money laundering. Using the OECD list as its basis, the Leaders of the Group of Twenty recently pledged to take sanctions against tax havens that do not share information in the fight against tax evasion and money laundering. ${ }^{3}$

Many scholars are skeptical about the effectiveness of this soft law practice as a means for disciplining offshore centers. A common argument often raised against this practice is that money laundering and bank secrecy are inextricably linked and combating financial crime can only be achieved by undermining confidentiality laws (Antoine, 1999). Other arguments are more specifically concerned with the lack of incentives to cooperate (Masciandaro, 2005). According to FitzGerald (2004), compliance with international regulations must be enforced especially on financial intermediaries, but while states may face international sanctions, there is no direct way to punish private sector actors, as they have no status under international law.

In the following, we take the position that successfully enforcing anti-money laundering standards relies on the existence of incentives to comply with these regulations. Rather than focus on the issue of national policymakers' compliance (Mascandiaro, 2005), we explore financial intermediaries' incentives to implement "know your customer" standards in order to identify and report dubious transactions. The reason is that this type of pressure hurts tax havens' reputations in the eyes of governments and investors and may thus lead to capital withdrawals

\footnotetext{
${ }^{1}$ Like Rose and Spiegel (2006), we define offshore financial centers as jurisdictions that oversee a disproportionate level of financial activity by non-residents.

${ }^{2}$ The IMF (2004) defines money-laundering as "a process in which assets obtained or generated by criminal activity are moved or concealed to obscure their link with the crime".

${ }^{3}$ See the official communiqué of the G20 London Summit $(02 / 04 / 2009)$ at http://www.londonsummit.gov.uk/resources/en/news/15766232/communique-020409
} 
and other economic damage.

The potential loss of reputation for banks that exhibit lax behavior towards anti-money laundering practices is critical for analyzing offshore financial intermediaries' choices in complying with controlling rules. In that context, we ask the following questions: Can reputation loss provide enough incentive for banks to respond appropriately? Can compliance occur in spite of the existence of bank secrecy? To address these issues, we develop a model that endogenizes the strategic choice of an offshore financial center between lax and scrupulous attitudes towards controlling the origins of investments. In that context, we assume that bank secrecy provided by the offshore center is not only a possible channel for illegal money transfers but also as an opportunity for legal financial services coupled with tax advantages (Antoine, 1999; Desai et al., 2006). Therefore we consider a two-country two-financial center model with two classes of investors. Ordinary investors seek the best investment return opportunity but feel some (preference or geographical) distance from the offshore financial center. Criminal investors seek opaqueness and use the offshore banks' secrecy policy to launder money that is illegally obtained and may be used for illegal purposes (e.g. illegal drugs, terrorism). In this paper, we conform to the standards of existing literature by endogenizing interest rates and government taxes. As is customary in the literature about banking competition and tax competition, we assume that financial centers compete to attract investors and that governments independently set taxes on interest payments. In addition to those actions, national or international institutions must decide to exert pressure on the offshore bank and country, for instance, through blacklisting policies and pressure on individuals who invest offshore.

The first objective of the paper is to highlight the winners and losers of pressure policies. Our second objective is to establish the conditions under which the offshore financial center is convinced to comply with scrupulous monitoring of an investor's identity and the origins of his/her funds, and therefore has the incentives to implement adequate customer due-diligence/knowyour-customer investigations. The third objective is to analyze the efficiency of the decision in terms of the effort required to blacklist an offshore center and to campaign against offshore investment. The fourth objective is to discuss the delegation of pressure policies against onshore institutions like tax administrations. Indeed, because offshore centers are very likely to be tax 
havens, anti-money laundering actions exerted by onshore institutions may also be (partially) motivated by the desire to reduce tax losses. The final objective is to study the impact of financial integration, entry of offshore financial centers and offshore jurisdiction size on banks' compliance and money laundering.

Our results may be summarized as follows: First, we show that offshore banks and countries lose under pressure policies. More interestingly, this conclusion also applies for any (noncriminal) onshore investors, individually or in the aggregate. Surprisingly, the implementation of a pressure policy might not only increase tax revenue, but also raise aggregate profits. This is because the pressure policy is not only likely to harm investors but also to weaken interbank competition. Second, we prove the existence of a pressure threshold above which the offshore financial center complies with international regulation. This threshold increases with the share of illegal investors and more interestingly with the degree of international financial integration. To be effective, this pressure policy should make ordinary investors incur a reputational harm that in monetary equivalent terms is larger than the banks' cost of monitoring investors.

Third, we derive the efficient pressure policy that a central planner who maximizes net world surplus could implement to enforce offshore financial center compliance. We find that this planner would exert the needed pressure on offshore centers only if the social cost of money trafficking exceeds a level that falls with deeper financial integration. Thus, deeper financial integration does not necessarily make money laundering more effective. Finally, the pressure strategies determined by national or international institutions whose objectives are biased towards tax revenue can be equal to or different from the efficient pressure strategies set by the above planner. We show that onshore institutions adopt efficient pressure strategies if the social cost of criminality is high enough. Otherwise, if the cost of exerting pressure and the cost of criminality are small, the onshore institution adopts an inefficient pressure policy, which is not enough to persuade the offshore financial center to comply. In that case, the fight against money laundering chiefly serves to mitigate international banking and tax competition.

Finally, we analyze the case where several offshore jurisdictions compete to attract onshore investors. We show that the combination of pressure policies and offshore competition can help the onshore government to fight criminality. In particular, offshore jurisdictions do not 
open international financial centers that are lax and launder money under the condition that their cost of setting up such a center is larger than the profits that would obtain from the criminal investments only. We also study the impact of jurisdiction size on the incentives to open an offshore financial center. We show that a jurisdiction incurs an opportunity cost that is proportional to its size so that only a small jurisdiction is enticed to open an international financial center. Such small jurisdictions can nevertheless be disciplined by an appropriate pressure policy.

Related literature: This paper relates to the existing literature in public economics and money laundering in offshore financial centers. The public economics literature often discusses the harm of offshore financial centers applying tax competition models to offshore capital. As explained by Wilson and Wildasin (2004) and Cremer and Pestieau (2004), much of the harm (resp., desirability) of tax competition hinges on the presence of benevolent (resp., Leviathan) governments. In particular, Slemrod and Wilson (2009) show that with the assumption of benevolent governments, the presence of tax havens worsens tax competition problems and that full or partial elimination of havens can improve welfare levels.

The present paper departs from the normative discussion of the desirability or harm of tax havens and instead focuses on the positive question about the compliance incentives of offshore banks and governments. Also, in contrast to the above literature, this paper makes more precise modeling of the banking sector by introducing interbank competition and capital holders' heterogeneity. Recently, Rose and Spiegel (2007) followed a similar approach in discussing a model with heterogeneous investors and (Stackelberg) competition between a domestic and offshore bank. An important aspect highlighted in Spiegel and Rose (2007) is that the existence of offshore financial centers generates pro-competitive effects on international banking activity. Our paper takes this point a step further by analyzing how this beneficial side effect impacts the efficient choice of a pressure policy and on governments' attitudes towards offshore centers.

Finally, the present paper also departs from the literature in its focus on money laundering. Instead of focusing on firms' avoidance of tax liabilities (e.g., Desai et al. 2006), our discussion concentrates on governments' fight against criminal activities and the threat that money 
laundering creates. This threat has been prominently highlighted in the aftermath of Sept. 11, 2001. In this direction, Masciandaro $(2005,2006)$ shows that in the absence of international law, onshore governments can fight criminal activity and reduce its cost by damaging the international reputation of offshore centers. Our model takes into account both features of tax competition and money laundering by introducing an ordinary and a criminal clientele.

The present paper is organized as follows: Section 2 presents the model, Sections 3 and 4 characterize the equilibrium in respect to offshore centers' compliance and noncompliance, Section 5 discusses the efficient pressure policy and delegation to onshore institutions. Section 6 presents two extensions of the supply and size of offshore jurisdictions. Section 7 presents our conclusions.

\section{Model}

We consider a two-country two-financial-center model. Let the onshore institutions be subscripted by $H$ (home) and the offshore ones by $F$ (foreign). The timing is as follows: First, national or international institutions decide to exert pressure on the offshore bank and country, for instance, by blacklisting policies and pressuring individuals who invest offshore. Second, offshore financial centers decide whether to monitor investment deposits. The offshore and onshore financial centers and governments simultaneously set their interest and tax rates on deposits. The offshore and onshore financial centers and governments simultaneously set their interest and tax rates on deposits. ${ }^{4}$ Third, investors choose the bank where they deposit their cash. Finally, the banks remunerate investors whereas investors pay their taxes on earned interests. We now describe each side of the financial centers.

Each financial center $i(i=H, F)$ collects funds from investors and offers a risk-free interest rate $r_{i}$. They invest those funds into risk-free assets that yield a given (world) rate of return $r$ and make a profit on the intermediation margin $r-r_{i}$. Here we consider a small offshore financial center that competes with a domestic financial center to attract investors located in the domestic jurisdiction. We thus underline the fact that offshore financial centers often have

\footnotetext{
${ }^{4}$ The timing of the tax and interest subgames does not qualitatively alter the results (see Picard and Pieretti 2009).
} 
very small populations and offer intermediation services predominantly to investors residing in large foreign economies. The offshore jurisdiction provides strict bank secrecy while the onshore center does not. It follows that the offshore financial center is more vulnerable to money laundering than other marketplaces where financial transactions are more transparent. Like Rose and Spiegel (2007), we consider that each jurisdiction contains only one bank. This allows us to focus on international financial competition. ${ }^{5}$

Financial centers are also asked to scrupulously monitor investors' identities and money origins. Because our focus is on the effect of the banks' monitoring of investors plays on the competition between financial centers and between governments, we simplify the monitoring technology by assuming that banks are able to discover the criminal identity and money origin of investors at a cost, $c$, proportional to the amount of monitored deposits. The main difference between the onshore and offshore financial centers is that the onshore financial center is obliged by law to comply with the monitoring of investors whereas the offshore center has no such obligation. Instead, the latter should be encouraged to monitor investors by onshore governments or international institutions. Therefore, the offshore financial center has an additional decision variable, $s \in\{m, o\}$, where $s=m$ denotes the scrupulous monitoring of the investors' money origins and $s=o$ indicates a lax behavior on this issue.

Investors lend their capital to the financial centers. All investors reside in the home country $H$ and are endowed with one unit of wealth that they deposit in the most advantageous financial center. The onshore economy contains $S$ investors and the offshore financial center is assumed to have no local investors. Investors split into an ordinary and a criminal clientele. On the one hand, we assume that there are $(1-\mu) S(4 / 5<\mu<1)$ criminal investors who only seek opaqueness to conceal the illegally obtained origins of their money. For simplicity we assume that those investors do not care about interest-earning and tax-saving: Their demand for opaqueness is perfectly inelastic to the offered return. Individuals with money laundering intentions are supposed to opt exclusively for the offshore bank when it does not scrupulously monitor financial transactions. If both jurisdictions do implement scrupulous monitoring, individuals who still seek opaqueness are supposed to look for another way of laundering money

\footnotetext{
${ }^{5}$ Competition is however imperfect, since we consider an international duopoly competing in offered interest rates.
} 
(e.g., in underground banking like casinos, hawalawa ${ }^{6}$...). We simplify our model by assuming that owners of illegal money have no such option. Finally, we assume that the social cost of each illegal dollar invested is equal to $\beta$. As a result, the social cost of the criminal activity is equal to $\beta(1-\mu) S$ when all criminal investors use the banking system. This parameter $\beta$ captures the social cost of this criminal behavior. It increases if the threat of criminality to society rises (as can be perceived in the U.S. after 9/11/2001). It also increases when substitute channels to the banking system for the money laundering business decrease and become less effective. In this case, the elimination of money laundering in the offshore financial centers brings greater social benefit. The cost is assumed to vanish when offshore financial centers monitor their investors.

On the other hand, the onshore country hosts $\mu S$ ordinary investors who invest money legally and thus favor the financial center that offers the highest net rate of return. Independent of tax and return considerations, we suppose that ordinary investors incur a cost of moving assets abroad that mainly reflects their reluctance to invest abroad. This reluctance may be explained by legal differences and poor information about remote areas that diminish investors' confidence in foreign financial centers. The reluctance may also reflect the geographical distance between investors and foreign centers, a factor that increases the perceived or actual cost of monitoring their investments. ${ }^{7}$ We therefore assume that ordinary investors are uniformly distributed along the unit segment according to their idiosyncratic reluctance to invest in the offshore banking sector. Consequently, we assume that the reluctance of an individual located at $x(x \in[0,1])$ is equal to the distance $x$ that separates him from the offshore center's characteristics multiplied by a (constant) unit cost $k$. Improvements in technology that bolster global integration by creating international links between financial markets and facilitate the access to foreign financial centers tend to lower transaction and information costs. The harmonization of (international) finance law also helps in reducing those costs. We thus interpret the

\footnotetext{
${ }^{6}$ Underground or ethnic banking systems are remittance systems that operate outside of (or parallel to) traditional financial channels. They are becoming more and more popular today as ethnic diasporas grow (Blum et al. 1998). The most commonly known informal systems are the Chinese chit or chop system of East and Southeast Asia, the black market peso exchange system of Latin America, and the hawala system, with its offshoot the hundi system in South Asia (FitzGerald, 2004) .

${ }^{7}$ Whereas Rose and Spiegel (2006) consider the heterogeneity of depositors in terms of individual wealth, we consider the heterogeneity of depositors in terms of their preferences for offshore financial centers.
} 
coefficient $k$ as measuring the degree of international financial integration. On the other hand, we consider that individuals seeking to conceal illegal money don't exhibit a preference for the home financial system.

Furthermore, following Sharman (2004), one dollar invested in a known place like the home country does not, all things being equal, correspond to the same amount being invested in an offshore center. Offshoring money will cause investors to endure a premium that is likely to increase with the loss of reputation of the destination jurisdictions in which they deposit. In this vein, Sharman (2004, p.12) observes that, "investors tend to avoid or leave jurisdictions with bad reputations not only out of concern that their money will be misappropriated, but also because firms risk harming their own reputations, as reflected in their share prices." Accordingly, to take account of the quality of the offshore center's reputation, we introduce a parameter $a$, which represents the disutility that non-criminal investor incur by offshoring their money in a financial center that does not scrupulously monitor the origin of its deposits. This parameter encompasses various sources of utility losses that the ordinary investor associates with a deposit in a bad financial center (e.g., in terms of patriotism, a warm glow, tax-evasion tagging). For the sake of convenience, we label this parameter $a$ as the "investor's reputational harm", although we do not intend to model any reputation game in this paper. Hence, the utility function of an investor located at $x$ who deposits in jurisdiction $i(i=H, F)$ is assumed to be given by

$$
U_{i}^{s}(x)= \begin{cases}r_{H}-t_{H} & \text { if } \quad i=H \text { and } s \in\{m, o\} \\ r_{F}-t_{F}-k \cdot x & \text { if } \quad i=F \text { and } s=m \\ r_{F}-t_{F}-k \cdot x-a & \text { if } \quad i=F \text { and } s=o\end{cases}
$$

In this definition, the investor's first option is to deposit in their home country, get the return $r_{H}$ and pay the tax $t_{H}$ per unit of deposit. The second option is to invest in the offshore financial center, get the return $r_{F}$ and pay the tax $t_{F}$ but incur a utility loss $k \cdot x$ that depends on the investor's reluctance to invest in the offshore center. Finally, when the offshore center does not monitor, it is put under pressure by international organizations. This collective action may be achieved through campaigns in the media, new regulations, publications of reports and statis- 
tics, categorization of tax havens and strategies of "naming and shaming". 8 In the following we assume that investors who offshore their money are also stigmatized by the international pressure campaign and, in turn, incur a(n) (individual) reputational harm $a$. We finally assume that

$$
\min \{r-c-k, r-a-k\}>0
$$

So that it is always efficient from the viewpoint of the offshore financial center to attract the most distant ordinary investor.

In this paper, the investor's reputational harm is an endogenous parameter that depends on the pressure that national and/or international institutions place on investors and the offshore financial center. Such institutions can put pressure on the offshore financial center by blacklisting them; they can put pressure on ordinary investors by informing them or campaigning about the risks of investing offshore, and by tagging and/or pursuing offshore investors, etc. We assume that the cost of exerting such a pressure is equal to $C(a)=\gamma a$. Finally, in accordance with standard tax competition literature, we assume that policy makers maximize their total tax proceeds, each one taking the tax of the other country as given.

We now derive the equilibrium deposit supplies, interest and tax rates when the offshore financial center either complies or does not comply with the scrupulous monitoring of investors.

\section{Compliant offshore financial center}

In this section, we derive the equilibrium of the sequential decisions of investors, banks and governments when each financial center decides to monitor the origin of invested funds and refuses to accept illicit money $(s=m)$. In this case, deposits are supplied only by ordinary investors who do not incur any disutility from being associated to an offshore bank.

The deposit supplies are obtained as follows. If the offshore financial center monitors, criminals are unable to use the banking system to launder money while the share of ordinary investors lending their money in offshore financial center is determined by the marginal

\footnotetext{
${ }^{8}$ For example, the Financial Action Task Force (FATF) adopted by 1999 a 'name, shame and punish' strategy for countries that refused to comply with its recommendations for anti-money laundering.
} 
(ordinary) investor $x_{F}$ who is indifferent between both jurisdictions. We readily obtain that

$$
x_{F}=\frac{1}{k}\left(r_{F}-r_{H}-t_{F}+t_{H}\right) \text { and } x_{H}=1-x_{F}
$$

As a result, the deposit supply functions are equal to $D_{i}=\mu x_{i} S(i=H, F)$.

On the one hand, financial centers $i(i=H, F)$ select the interest rates that maximize their profits $\Pi_{i}$ by taking as given the taxes and the rival's interest rate. That is, $\max _{r_{i}} \Pi_{i}=$ $\left(r-r_{i}-c\right) D_{i}=\mu\left(r-r_{i}-c\right) x_{i} S$ where $c$ is the monitoring cost. On the other hand, each policy-maker $i$ individually chooses her tax rate $t_{i}$ that maximizes her total tax proceed $T_{i}$, taking the other country's tax as given. That is, $\max _{t_{i}} T_{i}=t_{i} D_{i}=t_{i} x_{i} \mu S(i=H, F)$. The best responses of financial centers and governments are given by

$$
\begin{aligned}
& \widetilde{r}_{H}=\frac{1}{2}\left(r-c-k+t_{H}+r_{F}-t_{F}\right) \text { and } \tilde{t}_{H}=\frac{1}{2}\left(k+r_{H}-r_{F}+t_{F}\right) \\
& \widetilde{r}_{F}=\frac{1}{2}\left(r-c+r_{H}-t_{H}+t_{F}\right) \quad \text { and } \quad \tilde{t}_{F}=\frac{1}{2}\left(t_{H}-r_{H}+r_{F}\right)
\end{aligned}
$$

As it is standard in the literature, interest and tax rates are strategic complement: an increase in one bank's interest rate triggers the rise of the other's bank interest rate. So do increases in tax rates. Accordingly, the interest rate differential is equal to $\widetilde{r}_{H}-\widetilde{r}_{F}=-\frac{1}{3}\left[k+2\left(t_{F}-t_{H}\right)\right]$. All taxes being equal, the onshore financial center sets a lower interest rate as it can take advantage of legal investors' preference for their home country. The equilibrium interest and tax rates are given by

$$
r_{H}^{m}=r-c-\frac{3}{5} k, \quad r_{F}^{m}=r-c-\frac{2}{5} k, \quad t_{H}^{m}=\frac{3}{5} k \quad \text { and } \quad t_{F}^{m}=\frac{2}{5} k
$$

where the superscript $m$ denotes the equilibrium variables in the monitoring case. Since $t_{H}^{m}-$ $t_{F}^{m}=\frac{k}{3}>0$, the onshore country always sets higher taxes. The offshore country sets a lower tax to attract a larger base of taxable deposits. Those results are consistent with the tax competition literature. Interest rates positive by (1). As the interest rate differential is equal to $r_{H}^{m}-r_{F}^{m}=-\frac{k}{5}<0$, the onshore financial center takes advantage of investor's reluctance to invest abroad and therefore sets a lower interest rate. Because the marginal offshore investor 
is given by $x_{F}^{m}=\frac{2}{5}$, the equilibrium supplies are equal to

$$
D_{F}^{m}=\frac{2}{5} \mu S \quad \text { and } \quad D_{H}^{m}=\frac{3}{5} \mu S
$$

whereas the banks' profits and tax proceeds write as $\Pi_{i}^{m}=T_{i}^{m}=\frac{k}{\mu S}\left(D_{i}^{m}\right)^{2}(i=H, F)$. In this model, banks and governments get the same revenues because of their symmetric positions in the interest and tax competition games. ${ }^{9}$

We now analyze the interesting case of a non compliant offshore financial center.

\section{Lax offshore financial center}

We now suppose that the offshore financial center does not monitor investors' identity and money origin $(s=o)$. In this case some pressure is exerted on investors who incur a reputational loss $a$. We derive the equilibrium of the sequential decision of investors, banks and governments in the following way.

When the offshore financial center is lax, criminal investors are able to launder money in the offshore center. The share of legal money invested in each financial center is determined by the marginal (ordinary) investor $x_{F}$ who is indifferent between both jurisdictions. We readily compute

$$
x_{F}=\frac{1}{k}\left(r_{F}-r_{H}-t_{F}+t_{H}-a\right) \quad \text { and } \quad x_{H}=1-x_{F}
$$

The deposit supply functions are equal to

$$
D_{F}=\left(\mu x_{F}+1-\mu\right) S \quad \text { and } \quad D_{H}=\mu x_{H} S
$$

Each financial center selects the interest rate that maximizes its own profit by taking as given the rival's rate. ${ }^{10}$ That is, we have $\max _{r_{F}} \Pi_{F}=\left(r-r_{F}\right) D_{F}$ and $\max _{r_{H}} \Pi_{H}=\left(r-r_{H}-c\right) D_{H}$. Again, each policy-maker $i$ determines her tax $t_{i}$ by maximizing her tax proceed $T_{i}=t_{i} D_{i}$ $(i=H, F)$ taking the other tax as a given. As before, it is readily shown that interest rates as

\footnotetext{
${ }^{9}$ See Picard and Pieretti (2009) for a Stackelberg game between governments and banks.

${ }^{10}$ When the offshore financial center adopts a lax behavior, it is not able to discriminate between criminal and ordinary customers because it does not control of the investors' identity and the origin of their funds.
} 
well as tax rates are strategic complement. The interest and tax rates in this Nash equilibrium are given by

$$
\begin{aligned}
& r_{H}^{o}=r-c-\frac{1}{5}(3 k+2 k \nu+a-c) \quad \text { and } \quad r_{F}^{o}=r-\frac{1}{5}(2 k+3 k \nu+c-a) \\
& t_{H}^{o}=\frac{1}{5}(3 k+2 k \nu+a-c) \quad \text { and } \quad t_{F}^{o}=\frac{1}{5}(2 k+3 k \nu+c-a)
\end{aligned}
$$

where the superscript $o$ denotes the equilibrium values under a lax offshore center and where

$$
\nu \equiv \frac{1-\mu}{\mu}<\frac{1}{4}
$$

is the relative share of criminal investors (criminal investors versus legal ones). Interest rates are positive by (1). At this equilibrium, the marginal investor who is indifferent between the financial centers is given by

$$
x_{F}^{o}=\frac{2}{5}(1-\nu)+\frac{c-a}{5 k}
$$

which belongs to the interval $[0,1]$ if and only if

$$
-k(3+2 \nu)<a-c<2 k(1-\nu)
$$

When $a-c$ is set above the highest boundary of this condition, investors' reputational loss $a$ is so strong that ordinary investors avoid investing in the offshore center. By contrast, when $a-c$ is set below the lowest boundary, the monitoring cost is so high that the onshore bank sets an interest rate that is unattractive for any ordinary investor. This last set of conditions (2) determines an non empty interval and will be assumed from now for the sake of simplicity. Note that both taxes are positive under conditions (2).

The equilibrium demands for deposits are then equal to

$$
D_{H}^{o}=\frac{1}{5}\left(3+2 \nu+\frac{a-c}{k}\right) \mu S \text { and } D_{F}^{o}=\frac{1}{5}\left(2+3 \nu+\frac{c-a}{k}\right) \mu S
$$

while banks' profits and tax proceeds simply write as $\Pi_{i}^{o}=T_{i}^{o}=\frac{k}{\mu S}\left(D_{i}^{o}\right)^{2}(i=H, F)$.

We can make the following remarks about tax and interest rate differentials. 


\subsection{Properties of tax and interest rates}

On the one hand, the interest rate differential is equal to

$$
r_{H}^{o}-r_{F}^{o}=-\frac{1}{5}[2 a+3 c+k(1-\nu)]<0
$$

So, the offshore bank sets higher interest rates. There are two reasons for this result. First, the offshore bank must raise its interest rate to attract legal investors who feel some reluctance (in terms of geographical or characteristics distance). This effect diminishes however as the financial market becomes more integrated (lower $k$ ). Second, the offshore bank must also set a higher interest rate than its competitor to attract legal investors who suffer some reputational harm when they are associated to a lax offshore bank $(a>0)$.

On the other hand, the tax differential between the onshore and offshore countries can be computed as

$$
t_{H}^{o}-t_{F}^{o}=\frac{1}{5}[2(a-c)+k(1-\nu)]
$$

This tax differential increases if investor's reputation is more strongly harmed by institutional pressures like blacklisting policy (larger $a$ ). The tax differential also increases if the onshore financial center has a smaller compliance cost (smaller $c$ ) as this change allows the onshore center to increase its offered interest rate and to attract more deposits. The tax differential increases if the number of legal money investors rises (smaller $\nu$ ) as this raises the demand for onshore deposits. Finally, the tax differential decreases with financial integration (smaller $k$ ). Deeper financial integration reduces banks' intermediation markups, which in turn limits each country's opportunity to raise more tax on local investments.

It is important to note that, in contrast to the monitoring case and to tax competition literature (e.g. Kanbur and Keen, 1993), the (large) onshore country does not always set the largest tax rate. Indeed, by (3), the onshore country sets a lower tax rate if and only if

$$
a<\bar{a} \equiv c-\frac{k}{2}(1-\nu)
$$

where $\bar{a}$ lies between the boundaries in conditions (2). The onshore country sets a lower tax rate 
if the investor's reputational harm is small enough compared to the monitoring cost. Higher monitoring costs oblige the onshore financial center to decrease the offered interest, reducing its markup and its attractiveness to investors. The onshore country is then forced to cut its tax rate. Similarly, a fall in investor's reputational harm makes the offshore center more attractive and forces the onshore country to cut its tax rate.

We now explore the effect on agents of an increase in the pressure on investors.

\subsection{Winners and losers}

In this section we show that the pressure on investors investing abroad does not only decrease criminality but it also softens bank competition, which increases bank profits and tax revenue and decreases offshore and onshore investors wealth.

The investor's reputational harm $a$ impacts on the deposit supplies, interest rates and taxes. Indeed, it can readily be shown that an increase in $a$ entices investors to move their investments from the offshore financial center to the onshore one $\left(d D_{H}^{o} / d a>0>d D_{F}^{o} / d a\right)$. To resist the outflow of investment, the offshore financial center raises its interest rate. By contrast, the onshore center can take advantage of a more captive set of investors and offers a less advantageous interest rate $\left(d r_{H}^{o} / d a<0<d r_{F}^{o} / d a\right)$. Since tax proceeds are congruent with profits, the offshore policy maker then reacts to the outflow of investors by relaxing her tax pressure whereas the onshore policy maker takes advantage of the repatriated investments by augmenting its tax pressure $\left(d t_{H}^{o} / d a>0>d t_{F}^{o} / d a\right)$. Hence, the offshore financial center and government are losers in this policy whereas the onshore center and governments are the gainers. It is then readily understood that the offshore financial lobbies and governments will be vividly opposed to the pressure policy whereas the onshore financial lobbies will be promoting it.

It is interesting to discuss the effect of investor's reputational harm on the aggregate surpluses of banks, governments and investors. Note firstly that the onshore financial center and government can gain more than what the offshore center and government lose. Indeed, it is 
readily shown that the aggregate profit $\Pi^{o}=\Pi_{H}^{o}+\Pi_{F}^{o}$ increases with larger $a$ if and only if

$$
\frac{d \Pi^{o}}{d a}=\frac{2 k}{\mu S}\left(D_{H}^{o} \frac{d D_{H}^{o}}{d a}+D_{F}^{o} \frac{d D_{F}^{o}}{d a}\right)=\frac{2 \mu S}{25 k}(a-\bar{a})>0
$$

where $\bar{a}$ is defined in expression (4). Therefore, the aggregate profit increases with the investor's reputational harm if and only if $a>\bar{a}$. In this case, ordinary investors who return to the onshore financial center accept a lower interest rate because they do no longer feel any reputational harm and also because they avoid their idiosyncratic reluctance cost to invest offshore. As a consequence, the onshore center is able to realize larger intermediation markups; its profit rises at a faster pace than the fall of offshore profits. It is remarkable that, by (4), this situation occurs if and only if $t_{H}^{o}>t_{F}^{o}$; that is, if the offshore country is a tax haven. This allows us to conclude that the aggregate profit increases with the investor's reputational harm if and only if the offshore country is a tax haven. Because profits are congruent with taxes, the same conclusion applies to tax revenues. So, when the offshore country is a tax haven, banks and governments could extract more revenues in the aggregate by supporting pressure on investors' reputation. Of course, their problem is that cooperation on those issues is hard to obtain.

We now look at the aggregate welfare of ordinary investors. In contrast to banks and governments, ordinary investors are always harmed by an increase in $a$. The ordinary investors' aggregate surplus

$$
V^{o}=\left(r_{H}^{o}-t_{H}^{o}\right) D_{H}^{o}+\left(r_{F}^{o}-t_{F}^{o}\right) D_{F}^{o}-a D_{F}^{o}-\frac{k}{2}\left(x_{F}^{o}\right)^{2} \mu S
$$

includes the net return of onshore investment, the net return of offshore investment minus the reputational harm a from pressure to offshore investors and finally the aggregate utility loss from their reluctance for the foreign center. Differentiating this with respect to $a$ yields

$$
\begin{aligned}
& \frac{d V^{o}}{d a}=\underbrace{\frac{d\left(r_{H}^{o}-t_{H}^{o}\right)}{d a}}_{-} D_{H}^{o}+\underbrace{\left[\frac{d\left(r_{F}^{o}-t_{F}^{o}\right)}{d a}-1\right]}_{-} D_{F}^{o} \\
& +\underbrace{\left(r_{F}^{o}-t_{F}^{o}-a-k x_{F}^{o}-r_{H}^{o}+t_{H}^{o}\right)}_{0} \underbrace{\frac{d x_{F}^{o}}{d a}}_{-} \mu S
\end{aligned}
$$


where the last term is nil by the definition of the marginal investor $x_{F}^{o}$ who is indifferent between the financial centers. We know from the above paragraphs that the return offered to onshore investors falls with larger reputational harm $\left.\left(d\left(r_{H}^{o}-t_{H}^{o}\right) / d a\right)<0\right)$, which reduces their net utility. By contrast, the return of offshore investors rises $\left.\left(d\left(r_{F}^{o}-t_{F}^{o}\right) / d a\right)>0\right)$ but this gain does not outweigh their reputational loss $a\left(d\left(r_{F}^{o}-t_{F}^{o}\right) / d a<1\right)$. Indeed, both the offshore financial center and government react to an increase in investor's reputational harm $a$ by raising the offered interest rate $r_{F}^{o}$ and decreasing the tax rate $t_{F}^{o}$; however they can not offer to those investors a net return $r_{F}^{o}-t_{F}^{o}$ that fully compensates for their reputational harm. In the aggregate, investors are thus negatively affected by the larger reputational harm. This is because the harm on investor's reputation does not only destroy the value of offshore deposits but it also weakens the competition that disciplines the onshore center. Hence, any lobby representing ordinary onshore investors or onshore investors, or both groups shall be reluctant to an increase in pressure resulting in a higher investor's reputational harm.

We now study the condition under which the offshore financial center is enticed to shift from a lax behavior to a scrupulous monitoring.

\section{$5 \quad$ Pressure policies and monitoring incentives}

National governments and international institutions usually put effort in improving the regulatory compliance of offshore financial centers and in deterring investors to deposit their funds in those centers. Common practices include lobbying for blacklisting of non compliant offshore financial centers or organizing information campaigns about investors' risks in depositing offshore. United States Patriot Act and several E.U. member states explicitly rely on the O.E.C.D. (and F.A.T.F.) blacklists in drawing up their own national blacklists of tax haven jurisdictions (Sharman, 2004).

As stated in Section 2, criminality generates a social cost $\beta(1-\mu) S$ whereas exerting pressure on offshore financial centers and investors has a cost $C(a)=\gamma a$. In addition to those costs, this paper has highlighted two additional costs, namely, the investor's reputational harm and the related weakening of banking competition. The purpose of this section is to discuss the balance 
between those costs. To be more precise, we here investigate about the efficient level of pressure policy $a$. We first determine the pressure policy that entices offshore banks to monitor. We secondly adopt a normative perspective by asking for the efficient pressure policy, which is the pressure that would maximize the welfare of both onshore and offshore countries. Finally, we present a positive discussion about a pressure policy that is delegated to onshore governmental agencies whose purposes are biased towards tax proceeds. The latter assumption is not too unrealistic as most OECD countries have designated their treasury and finance ministries as lead participants in the Basel committees and in the Financial Action Task Force (FATF) ${ }^{11}$. In this respect, the Economist (2001, p.66) wrote: "some suspect that the O.E.C.D. would like to use the fight against money laundering to advance its parallel and controversial campaign against an activity it calls "unfair" tax competition [...]". In addition, the G20 leaders have recently agreed to stand ready to deploy sanctions to protect their public finances (OCDE, 2010). For each case we discuss the impact of financial integration on the pressure policy.

\subsection{Offshore monitoring incentives}

The offshore financial center has an incentive to monitor the investor's identity and money origin if its profit is larger under monitoring than under lax behavior. That is, if

$$
\Pi_{F}^{m}-\Pi_{F}^{o}=\frac{k}{\mu}\left[\left(D_{F}^{m}\right)^{2}-\left(D_{F}^{o}\right)^{2}\right]
$$

is positive. For any a satisfying conditions (2), this happens if $D_{F}^{m}>D_{F}^{o}$, or if

$$
a>a_{F} \equiv c+3 k \nu
$$

where $a_{F}$ defines the threshold of investor's reputational harm above which the offshore financial center voluntarily complies and where $a_{F}$ satisfies condition (2). The offshore center should

\footnotetext{
${ }^{11}$ The Financial Action Task Force (FATF) is an inter-governmental organisation whose purpose is the development and promotion of national and international policies to combat money laundering and terrorist financing. Out of 34 member countries, the lead authority in FATF delegations has been granted to Treasury or Finance ministries/agencies for more than 16 countries including Canada, France, Germany, Italy, Sweden, U.K. and U.S.A..
} 
suffer a sufficient demand loss (through larger $a$ ) to choose to monitor its investors. Note firstly that the investor's reputational harm $a$ should be set higher than the bank's monitoring cost $c$. This reflects the fact that the offshore center must be enticed to forego its profit on illegal money investors. If the number of illegal investors rises, the pressure exerted on ordinary investors should be even stronger (indeed, $a_{F}$ increases with $\nu$ ). Note secondly that the offshore center is more likely to monitor its investors for higher degree of international financial integration (smaller $k$ ). Indeed, financial integration hurts more the lax offshore center because the latter must cut its intermediation margin not only on the ordinary investors but also on the captive criminal ones.

\subsection{Efficient pressure strategies}

We now discuss the optimal pressure exerted by a benevolent social planner who maximizes an objective that encompasses the economic surplus of both countries and the criminality damage in the onshore country as follows:

$$
W=\sum_{i=H, F}\left(V_{i}+\Pi_{i}+T_{i}\right)-\gamma a-\beta(1-\mu) S
$$

where $\gamma a$ is the social cost of exerting pressure $a$ and where $\beta(1-\mu) S$ is the social cost attached to the use of the banking system to criminal activity. The latter cost vanishes when the offshore financial center monitors its investors.

The economic surplus can readily be computed given that the total mass of ordinary investors is constant and equal to $\mu S$. For every unit of investment, the investor, the bank and the government share the risk-free rate interest $r$. Indeed, the investor earns $r_{i}-t_{i}$, the bank $r-r_{i}$ and the government $t_{i}$, which all add up to $r$. In addition, an offshore investor suffers from reputational losses from the pressure $a$ and from the reluctance $k x$ for investing in the offshore center. The banks incur the $\operatorname{cost} c$ when they monitor their investors. Therefore, if the planner exerts a sufficient pressure to entice the offshore financial center to monitor $\left(a \geq a_{F}\right)$, 
the above objective writes as

$$
W^{m}(a)=\left[r-\frac{1}{2} k\left(x_{F}^{m}\right)^{2}-c\right] \mu S-\gamma a
$$

This function obviously decreases in $a$. If the planner exerts a too low pressure $a\left(0 \leq a<a_{F}\right)$, the offshore center does not monitor. The objective writes as

$$
W^{o}(a, \beta)=\left[r-\frac{1}{2} k\left(x_{F}^{o}\right)^{2}-a x_{F}^{o}-c x_{H}^{o}\right] \mu S+\left(r-r_{F}^{o}\right)(1-\mu) S-\gamma a-\beta(1-\mu) S
$$

The first term in the square bracket includes the economic benefit induced by ordinary investors minus the welfare loss caused by their reluctance to invest in the offshore bank and their reputational loss $a$ and minus the monitoring cost in the onshore center. The second term represents the offshore economic benefit of accepting illicit money and making an earning on it (though the earning of illicit money holders $r_{F}^{o}$ is nevertheless not considered by the planner). The third term is the cost of exerting pressure and the last term the social cost of criminality.

Differentiating this objective by $a$, we get

$$
\begin{aligned}
\frac{d W^{o}}{d a} & =\left[\left(-k x_{F}^{o}-a+c\right) \frac{d x_{F}^{o}}{d a}-x_{F}^{o}\right] \mu S-\frac{d r_{F}^{o}}{d a}(1-\mu) S-\gamma \\
& =\frac{S}{25 k(1+\nu)}\left[9\left(a-a_{F}\right)+2 k(15 \nu-4)\right]-\gamma
\end{aligned}
$$

where the square bracket in this expression is negative under $a<a_{F}$ and $\nu<1 / 4$. Hence, the economic surplus decreases with stronger pressure and investor's reputational loss $a$. As mentioned above, the investor's reputational loss does not only destroy value for offshore investors but it also reduces the onshore's investor surplus through the effect of relaxing the competition for the benefit of the onshore financial center.

Because both objectives decrease in $a$ on their respective supports, the planner's optimal pressure strategy is to set the smallest value of $a$ on each support. As a result the planner sets either $a=0$ if $W^{m}\left(a_{F}\right)<W^{o}(0, \beta)$ or $a=a_{F}$ if $W^{m}\left(a_{F}\right) \geq W^{o}(0, \beta)$. Given that the objective $W^{o}$ decreases in $\beta$ we can infer the following proposition:

Proposition 1 There exists a threshold $\widetilde{\beta}$ for the social cost of criminality such that the social 
planner exerts no pressure if $\beta<\widetilde{\beta}$ and exerts the pressure $a=a_{F}$ otherwise.

In her decision, the planner balances the social cost of criminality against the cost of reduced competition. The unexpected property of our model is the dichotomy in the pressure policy. Such a dichotomy stems from the fact that offshore banks are homogeneous and make the same monitoring choices at $a=a_{F}$ and the facts that there the welfare objective has a jump at $a=a_{F}$ and falls in the ranges above and below this threshold. The reader will note that such a dichotomy is robust to alternative assumptions. For instance, if banks were heterogeneous with respect to their monitoring costs, they would nevertheless need to coordinate their monitoring decisions to a same threshold because the investors' reputation harm is attributed to the financial center rather than to any single bank. Also, if criminals were heterogeneous with respect to their preferences to launder money abroad, the total investment supply in offshore banks would still differ under monitoring and lax behaviors and would still trigger a dichotomous change in the offshore banks' monitoring decisions. Finally, the fact that welfare objective decreases with the pressure policy emanates from the direct cost that the pressure policy imposes on the government and from the indirect cost that the reputation harm imposes on both investors and banks. The pressure policy is a harm on investors, which would be suppressed in the absence of criminality. Changes in the specification of the investors' supply functions would not alter such a property.

We now turn to the issue of financial integration. How does the pressure policy change when differentiation between financial centers falls (smaller $k$ )? Differentiating totally the equality $W^{m}\left(a_{F}\right)-W^{o}(0, \widetilde{\beta})=0$ we get

$$
\frac{d \widetilde{\beta}}{d k}=-\frac{\frac{d}{d k}\left[W^{m}\left(a_{F}\right)-W^{o}(0, \widetilde{\beta})\right]}{\frac{d}{d \beta}\left[W^{m}\left(a_{F}\right)-W^{o}(0, \widetilde{\beta})\right]}=3 \gamma \frac{1+\nu}{S}-\frac{1}{50 \nu}\left(9 \frac{c^{2}}{k^{2}}-28 \nu-26 \nu^{2}\right)
$$

where $\nu<1 / 4$. This expression reflects the opposite effects of financial integration on the direct cost of pressure policies and the economic inefficiency they generate. On the one hand the first term of the latter expression shows the effect of financial integration on the cost of the pressure policy, $\gamma a_{F}$. As mentioned earlier, a fall in $k$ decreases the profit of the offshore financial center more in the lax scenario than in the monitoring case. As a consequence, the threshold $a_{F}$ falls 
with smaller $k$ so that financial integration increases the effectiveness of the pressure policy. The planner therefore needs to exert a weaker pressure to entice the offshore bank to comply to then monitoring their investors. This effect is naturally more important for higher cost of exerting pressure, $\gamma$. On the other hand, the second term in the last expression reflects the effect of financial integration on the economic surplus generated by the whole banking sector when the offshore bank is lax. In particular, a fall in $k$ decreases the number of onshore investors and therefore the bank's cost of monitoring. This cost saving in the banking industry generates an economic surplus that increases with weaker pressure policies. Hence, the planner has an incentive to refrain from exerting a pressure policy and to exert the pressure policy $a_{F}$ for higher costs of criminality $\beta$. To sum up, financial integration makes the pressure policy more effective but more harmful for the efficiency of the banking sector. Which effect dominates depends on the cost of exerting pressure, $\gamma$. Indeed,

$$
\frac{d \widetilde{\beta}}{d k}>0 \Longleftrightarrow \gamma>\widehat{\gamma} \equiv \frac{S}{150 \nu(1+\nu)}\left(\frac{9 c^{2}}{k^{2}}-28 \nu-26 \nu^{2}\right)
$$

The threshold $\widehat{\gamma}$ is more likely to be positive if the economy includes fewer criminals (smaller $\nu)$.

Proposition 2 As financial markets integrate (smaller $k$ ), the social planner is more likely to entice the offshore bank to monitor by exerting the pressure $a=a_{F}$ if and only if $\gamma>\widehat{\gamma}$.

This proposition also qualifies the usual claim stating that financial globalization fosters criminality. We have here shown that deeper financial integration encourages compliance by offshore centers. It furthermore entices the social planner to use this pressure when the cost of financial criminality is high enough compared to the cost of reducing interbank competition. Under this condition, financial globalization reduces financial criminality.

The present analysis has relied on the unlikely existence of a social planner that aggregates the interests of all (non-criminal) participants in the economy. As stated above, pressure on offshore centers is discussed, negociated and then implemented by international bodies which comprise delegation of various member states whose objectives might be biased towards tax revenues. This is the topic of the next section. 


\subsection{Delegating pressure policies to an onshore agency}

We now discuss the case where the decision on the pressure policy is delegated to the onshore tax agency. Such a delegation is indeed likely to arise because governments have a fiscal interest in eliminating fraud and because tax administrations are equipped with audit instruments to check/threaten tax payers who possess offshore bank accounts. In addition since onshore tax proceeds are aligned with onshore profits, such a delegation can readily get the support of the onshore banks' lobby. We here show how such a delegation strategy can be socially inefficient.

In this context, we assume that the onshore institution maximizes the tax proceed minus the social cost of criminality net of the cost of the pressure policy, which is equal to $\Omega^{o}(a, \beta)=$ $T_{H}^{o}(a)-\gamma a-\beta(1-\mu) S$ if $a<a_{F}$ and $\Omega^{m}(a)=T_{H}^{m}-\gamma a$ if $a \geq a_{F}$. We now derive the optimal pressure policy chosen by this institution.

Let us first look at the case where the offshore financial center is enticed to monitor its investors $\left(a \geq a_{F}\right)$. Then, neither the onshore tax proceeds nor the criminality level depend on the level of the pressure policy $a$. As a result, the onshore institution optimally sets $a=a_{F}$. Let us then consider the case where the offshore financial center is not enticed to monitor its investors $\left(a<a_{F}\right)$. As noted in Section 4.2, the onshore tax proceeds $T_{H}^{o}(a)$ is an increasing and convex function of $a$ (because $T_{H}^{o}(a)$ rises with $D_{H}^{o}(a)$ which is a linearly increasing function of $a$ ). So, from the onshore taxation point of view, there always exists an incentive to raise the pressure policy and set $a$ above zero. However, the choice of the pressure policy also has a cost $\gamma a$. Since the net tax benefit $T_{H}^{o}(a)-\gamma a$ is a convex function of $a$, the optimal pressure policy on the interval $\left[0, a_{F}\right)$ must be either $a=0$ or $a=a_{F}-\varepsilon$, where $\varepsilon>0$ is infinitely small. The second pressure policy, $a=a_{F}-\varepsilon$, is explained by the fact that the onshore institution (as well as the onshore banks) has an incentive to deter ordinary investors from offshoring their money. Such a deterrence strategy increases investors' demand for the onshore center and raises onshore profits and taxes. In addition, the onshore institution also has an incentive to entice illegal money investors to go to the offshore bank. Indeed, because the offshore bank will take advantage of this captive clientele, it will be able to lower its offered interest rates so that the demand for the onshore bank will be boosted. The following proposition presents a 
full characterization of the pressure policy.Let

$$
\begin{aligned}
\bar{\gamma} & =\frac{k(6+7 \nu)-c}{25 k(1+\nu)} S \\
\beta_{1} & =k\left(\frac{6}{5}+\nu\right) \text { and } \beta_{2}(\gamma)=\gamma \frac{(1+\nu) a_{F}}{\nu S}+\frac{(2 k \nu-c)(6 k+2 k \nu-c)}{25 k \nu}
\end{aligned}
$$

Proposition 3 The optimal pressure policy of the onshore institution is to implement

(i) no pressure if $\gamma>\bar{\gamma}$ and $\beta<\beta_{2}(\gamma)$,

(ii) the pressure policy $a^{*}=a_{F}-\varepsilon$ if $\gamma<\bar{\gamma}$ and $\beta<\beta_{1}$ and

(iii) the pressure policy $a^{*}=a_{F}$ if $\beta>\max \left\{\beta_{1}, \beta_{2}(\gamma)\right\}$

Proof. See Appendix A.

Insert Figure 1 here

Figure 1 illustrates the optimal pressure policy for parameters $(\gamma, \beta)$. According to this Figure and to Proposition 3, the onshore institution implements no pressure if the social cost of criminality is low enough and the cost of the pressure policy is high. It implements the pressure level $a_{F}-\varepsilon$ if the social cost of criminality is low and the cost of the pressure policy is low. Finally, it implements a pressure policy that eliminates criminality through active monitoring by the offshore financial center if the social cost of criminality is high enough.

The pressure policy of the onshore institution is not fully aligned with the social planner's choice. In particular, if the cost of exerting pressure and the cost of criminality are small enough, the onshore organization exerts a pressure but never to the point where the offshore financial center monitors. It rather uses the pressure policy to relax interbank competition and repatriate investments back to the onshore bank. This interesting result highlights the impact of the tax repatriation motives in the fight against money-laundering. Such motives can indeed eliminate the incentives to have offshore financial centers actually comply with "know-yourcustomer" and reporting regulations. Hence, such a pressure policy, presented under the label of a fight against criminality, may in fact be diverted to the objective of tax collection, with the blessing of onshore financial centers. 
The result stated in Proposition 3 relies on the same dichotomy and discontinuity properties as discussed for Proposition 1. A main difference is that the onshore tax revenue is an increasing and convex function of the pressure policy. As a result, the tax agency may find it profitable to push its pressure level up as long as the offshore financial center chooses a lax behavior. Such a convexity property stems from the existence of increasing returns from the pressure policy $a$. Indeed, a rise in $a$ does not only entice onshore investors to rappatriate their investment from abroad but it also decreases their claims on onshore interest payments. So, the pressure policy raises (multiplicatively) both the number of onshore investors and the mark-ups and taxes that onshore financial center and government can impose.

How does this pressure policy change when financial integration increases (smaller $k$ )? It is firstly readily seen that $\bar{\gamma}$ decreases to zero and becomes negative as $k$ falls. The intuition is that smaller differentiation between financial markets does not only reduce profits but also tax proceeds. So, the onshore institution is less enticed to exert pressure for tax motives. Secondly, the threshold $\beta_{1}$ also falls to zero with smaller $k$. Those two properties imply that the set of parameters for which the tax agency sets the inefficient pressure policy $a^{*}=a_{F}-\varepsilon$ shrinks as $k$ falls. Financial integration therefore diminishes the incentives for the tax agency to set such an inefficient pressure policy.

\section{Offshore jurisdiction supply and size}

In this section we discuss the impact of pressure policies on the size and supply of offshore jurisdictions. We highlight several facts. First, large jurisdictions are served by only a small set (if not a singleton) of dominant offshore centers and those jurisdictions have small populations. For example, the Cayman Islands and the Bahamas host the largest banking services directed towards U.S. clients, ${ }^{12}$ Jersey and Guernsey towards British customers, Hong Kong towards various other Southeast Asian countries, Luxembourg towards its neighboring countries Germany, France and Belgium, Liechtenstein towards Germany, etc. Two reasons underlie the small number of offshore jurisdictions hosting an active international financial center. The first is that there seems to be strong legal and cultural product differentiation according to the

\footnotetext{
${ }^{12}$ The Cayman Islands host more than $40 \%$ of offshore assets in 2001 according to Oral et al. (2005).
} 
onshore jurisdiction that is served. Many offshore jurisdictions have historical and legislative links with their offshore jurisdictions. Legislative links help promote and adapt advantageous financial legislation in the offshore jurisdictions while historical or jurisdictional links help appease international relations with onshore jurisdictions. ${ }^{13}$ On the other hand, because offshore services often lack product differentiation, competition is fierce amongst the offshore jurisdictions and financial centers that want to serve the same onshore customers. As a result, many jurisdictions have incentives to forgo establishing or maintaining their legal advantages in order to limit the offshore centers that serve the same class of customers. As shown by the cases of Haifa and Cuba, who were replaced by Beirut and the Bahamas after World War II (Palan, 1998), changes in offshore dominance can be dramatic.

In this section, we extend the previous model to discuss the economic impact of a large supply of offshore jurisdictions on pressure policies. We then study the effect that the size of the offshore jurisdiction has.

\subsection{Supply of offshore centers}

We now study the issue of the supply of offshore centers. When many offshore centers compete for clientele from the same onshore center, the offshore financial market is rarely profitable. The onshore government eliminates criminal investments by preempting profitable activity in the offshore banking market.

We assume that the offshore jurisdictions $l=1,2, \ldots, N$ are present in the international financial market that is considered by onshore investors. All offshore banks make their monitoring decisions and then governments and financial centers make their decisions over tax and interest rates. The difficulty of the present analysis lies in combining simultaneous competition over interest and tax rates with the presence of two groups of perfectly mobile ordinary and criminal investors. While the formal analysis is presented in the Appendix, we present here the main results.

Both offshore governments and banks play a Bertrand competition game in terms of tax

\footnotetext{
${ }^{13}$ For instance, the Cayman Islands, Bermuda, the Virgin Islands, Jersey, Gernsey, and the Netherlands Antilles are or have been Overseas Territories or Crown Dependencies of the U.K, the Netherlands or the U.S.A.. Luxembourg and Monaco's law were inspired by French law and recently updated to E.U. legislation. Monaco's military defense is the responsibility of France. Liechtenstein's diplomacy is delegated to Switzerland.
} 
and interest rates. Each offshore financial center $l$, has an incentive to attract onshore ordinary investors by offering the highest return net of tax or reputation loss; that is, either $r_{l}-t_{l}$ when it monitors or $r_{l}-t_{l}-a$ when it is lax. They also have incentives to attract criminal investors who incur no reputation losses. Similarly, the offshore jurisdiction 1 also has incentives to attract investors by diminishing its tax rate. The equilibrium interest and tax rates depend on the configurations of the set of monitoring decisions. Jurisdictions offer their maximal interest rates and set their taxes to zero in all configurations, except where only a single compliant or a single lax jurisdiction exists. Such equilibria are reminiscent of the tax and banking competition literature that emphasizes the possibility of a race to the bottom in taxes and intermediation margins. In the presence of lax centers, criminal deposits still exist but they benefit neither offshore lax banks nor their jurisdictions.

In configurations where there is only one center in the group of compliant or lax centers, the effect of competition is less dramatic. In both cases there will be profit to share between this financial center and its government. On the one hand, if there is only one monitoring center, this center is profitable and yields tax revenues if $c<a$. Indeed, the monitoring center is able to offer the interest rate $r-a$, which cannot be overbidden by lax centers even though they must set their highest rate at $r$ because of the competitive pressure amongst themselves. The monitoring jurisdiction generates the following profit from its margin $a-c$ between the lax centers' reputational harm and its own monitoring cost:

$$
\Pi_{F 1}=(a-c)(2 k-a+c) \frac{\mu}{3 k} S
$$

This strategy is profitable only if $c<a$. On the other hand, if only one lax center exists, this center may generate the value

$$
\Pi_{F N}=r(1-\mu) S
$$

by targeting only on criminal investors, whereas it can generate the value

$$
\bar{\Pi}_{F N}=(c-a)[(3-\mu) k+2 a \mu] \frac{1}{3 k} S
$$

by attracting both criminal and ordinary investors, which is profitable only if $c>a$. In the 
Appendix we determine the configurations of monitoring decisions that are Nash equilibria.

From this analysis, we can infer that a large supply of offshore centers is detrimental for jurisdictions and banks. In the absence of offshore product differentiation, competition significantly reduces offshore profits and tax revenues. It also reduces onshore profits and tax revenues. Competition does not however prevent offshore banks from offering investment prospects for criminals so that pressure policies are ineffective.

Pressure policies nevertheless become effective when offshore jurisdictions incur costs in establishing and maintaining their international financial centers. Such costs are indeed not negligible. International financial centers require supervisory bodies and auditing institutions. Criminals also need the trust in and the reliability of offshore bank institutions and products. In addition, offshore jurisdictions need to design appropriate laws for financial products and institutions, pay for utilities, offices, supplies, and advertising for their own center. According to Williams et al. (2005, p. 1180), "taking the estimated cost of complying with international standards into accounts reduces the overall revenues by about 0.3 per cent of GDP." Those costs can be so high that only the offshore tax revenues from criminal investors are not able to cover them.

So let the offshore jurisdiction's cost of setting up an international financial center be given by $K>\Pi_{F N}$. If this cost is also larger than the maximal offshore tax revenues, then no offshore jurisdiction will find it beneficial to open an international financial center that would choose lax behavior. By (6), the onshore government can reduce $\bar{\Pi}_{F N}$ by setting a reputation harm $a$ sufficiently high and close to the monitoring cost $c$.

Proposition 4 Suppose that the cost of setting up an international financial center is larger than the profits obtained only on criminal investments $\left(K>\Pi_{F N}\right)$. Then, there exists a threshold $a_{F N}\left(a_{F N}<c\right)$ such that no offshore jurisdiction opens/supports a lax international financial center if $a \geq a_{F N}$.

\section{Proof. See Appendix B.}

As a result, the combination of pressure policies and offshore competition helps the onshore government to fight criminality. As a case in point, the pressure policy required to hinder 
criminals' investments in a competitive offshore market is smaller than the pressure policy $a_{F}$ that was needed to eliminate criminal deposits in an offshore monopoly $\left(a_{F N}>a_{F}\right)$.

We conclude this discussion with two observations. First, the cost of setting up an international financial center also has implications for the entry of offshore jurisdictions in the international financial market. Indeed, because of offshore banking competition, only one or a few offshore jurisdictions and financial centers may be enticed to enter and/or survive. As a result, incumbent offshore jurisdictions may benefit from first-mover advantage, as potential entrant jurisdictions may prefer not to sink the initial cost of establishing an international financial center. Similarly, tacit collusion amongst the few offshore jurisdictions may help sustain higher taxes and lower net returns for investors. In this case, the onshore government must fight criminality in the same manner as the monopoly offshore jurisdiction discussed in the previous sections.

Second, although competition in the offshore banking market increases investors' returns, it harms the onshore banking industry and diminishes tax proceeds. Because of the larger investors' surplus, a benevolent social planner (who maximizes the economic surplus of all countries minus criminality damage in the onshore country) is likely to choose a policy promoting an appropriate pressure policy and the entry of many offshore financial centers. In contrast, when the policy towards offshore centers is delegated to the onshore tax agency, the latter agency is likely to choose a policy promoting the concentration of the offshore banking sector in a single jurisdiction and that sets the inefficient pressure level $a_{F}-\varepsilon$.

We now turn to the issue of the impact of jurisdictional size on pressure policies.

\subsection{Offshore jurisdiction size}

We now clarify the role of an offshore jurisdiction's size on its choice to host an offshore international finance center. Our main argument is that each offshore jurisdiction and financial center trades off the benefits of targeting local investors and attracting foreign investors. In most offshore jurisdictions, local investors represent a small less-informed and less mobile group. In opening an international financial center, each jurisdiction incurs an opportunity cost equal to the amount of taxes lost on local investors. As a result, a smaller jurisdiction is more likely 
to open an offshore international financial center because the smaller group of local investors yields a smaller opportunity cost.

To develop this point, we assume a single offshore center that hosts a mass $L_{F} \equiv \mu S l_{F}$ of local homogenous investors who do not invest abroad and, naturally, are not harmed by the pressure policy. They invest their money in their local banking system only if they get a positive net return $r_{F}-t_{F}$. As before, the offshore financial center chooses its monitoring strategy and then both onshore and offshore financial centers and jurisdictions independently set their interest and tax rates $\left(r_{i}, t_{i}\right), i=H, F$.

The presence of local investors changes the investment supply of the offshore financial center and therefore alters the latter's strategy. To attract onshore investors, the offshore financial center must raise its interest rates and forgo the profits on local investors. Similarly, the offshore government attracts onshore investors by cutting their tax rates and forgoing the tax revenues on local investors. Let $r$ and $t$ denote the tupples $\left(r_{H}, r_{F}\right)$ and $\left(t_{H}, t_{F}\right)$. Let $\Pi_{i}(r, t)$ and $T_{i}(r, t)$ be the profits and tax revenues if the offshore center attracts onshore ordinary investors. Let $\Pi_{F}^{A}(r, t)$ and $T_{F}^{A}(r, t)$ define the offshore center's profits and tax revenues under autarky when it does not attract any international investors. Autarkic profits and tax revenues increase with the mass of offshore local investors. The equilibrium is defined as the Nash equilibrium of the tax and interest rate games such that $r_{H}^{*}=\arg \max _{r_{H}} \Pi_{H}\left(r_{H}, r_{F}^{*} ; t^{*}\right), r_{F}^{*}=$ $\arg \max _{r_{F}}\left\{\Pi_{F}\left(r_{H}^{*}, r_{F} ; t^{*}\right), \Pi_{F}^{A}\left(r_{H}^{*}, r_{F} ; t^{*}\right)\right\}, t_{H}^{*}=\arg \max _{t_{H}} T_{H}\left(r^{*} ; t_{H}, t_{F}^{*}\right)$ and $t_{F}^{*}=\arg \max _{t_{F}}$ $\left\{T_{F}\left(r^{*} ; t_{H}^{*}, t_{F}\right), T_{F}^{A}\left(r^{*} ; t_{H}^{*}, t_{F}\right)\right\}$.

If the number of local investors is small, banks and governments are able to set low interest rates and high enough tax rates so that they can obtain a profit higher with ordinary investors than without them. For instance, under monitoring behavior, the offshore equilibrium interest and tax rates are then given

$$
r_{F}^{*}=r-c-\frac{1}{5} k\left(2+3 l_{F}\right) \quad \text { and } \quad t_{F}^{*}=\frac{1}{5} k\left(2+3 l_{F}\right)
$$

As is apparent, a larger mass of local investors $l_{F}$ prevents the offshore banks from raising their interest rate while enticing the offshore government to raise more taxes. Therefore, offshore jurisdictions with larger groups of local investors are weaker competitors and may avoid opening 
an offshore international financial center. The same conclusion holds under lax behavior. We then get the following proposition:

Proposition 5 There exist two numbers of local investors $l_{F}^{1}$ and $l_{F}^{2}$ such that the offshore jurisdiction supports/opens an offshore international financial center if $l_{F} \leq l_{F}^{1}$ and such that the offshore jurisdiction and center concentrate on their local investors if $l_{F} \geq l_{F}^{2}$. In the former case, there exists a threshold $a_{F}$ such that the onshore center monitors if $a \geq a_{F}$ and both Propositions 1 and 3 apply.

\section{Proof. See Appendix C.}

As a result, jurisdictions with a larger number of local investors are less likely to be open to international financial competition. When they are, their local investment size makes them weaker competitors. The present discussion offers an explanation about why offshore centers with small populations and investor bases are more effective in attracting international investors. For instance, jurisdictions like the Cayman Islands are good candidates: in 2001, they collected some US\$13.82 million in total assets per capita, far more than the investment needs of a local population of just 56,000 who work predominantly in the tourism industry.

\section{Conclusion}

International and national institutions pressure offshore financial centers and their clients to comply with anti-money laundering regulations. Many observers consider such a soft-law practice as inefficient in combating money laundering by financial institutions. They claim that money laundering and bank secrecy are inextricably linked and that only by undermining confidentiality laws can the fight against financial crime be achieved. In this paper, we discuss such pressure policies and assess their impact on money laundering. We employ a two-country two-financial center model with ordinary and criminal investors. Our modeling strategy fits with the standards of the economic literature not only in allowing interbank competition, but also by modeling the tax competition between the onshore and offshore financial centers. This modeling strategy allows us to discuss the winners and losers of such pressure policies in a clear-cut way. We show that aggregate profit and tax revenues can increase under the effect of 
pressure policies because such policies can reduce interbank and tax competition. In addition, we demonstrate that offshore banks will comply with scrupulous monitoring of investors' identities and the origin of their funds when the pressure has the potential to create sufficient harm to an investor's reputation. We find that an efficient pressure policy is dichotomous in the sense that a social planner chooses zero pressure or just enough pressure for compliance. We also show that the implementation of pressure policies by an onshore tax institution may be inefficient as they can be biased towards the banking sector's profits and can therefore never eliminate criminal activity. Finally, we qualify the claim stating that deeper financial integration fosters financial criminality. In this model, financial integration reduces financial criminality. Such results are not qualitatively altered by the presence of many offshore jurisdictions or the fact that the latter host a small group of local investors.

\section{References}

[1] Abbott, K.W., Snidal, D., 2000. Hard and Soft Law in International Governance. International Organization 54, 421-56.

[2] Antoine, R.-M., B., 1999. The Protection of Offshore Confidentiality: Policy Implications and Legal Trends. Journal of Financial Crime 7, 9-25.

[3] Basel Committee on Banking Supervision, 2001. Customer Due Diligence by Banks, consultative document. Basel. Bank for International Settlements.

[4] Cremer, H., Pestieau, P., 2004. Factor mobility and redistribution, Handbook of Regional and Urban Economics, in: J. V. Henderson \& J. F. Thisse (ed.), Handbook of Regional and Urban Economics, edition 1, volume 4, chapter 57, 2529-2560.

[5] Desai, M. A., Foley, C. F. Hines, J. R., 2006. The demand for Tax Haven Operations. Journal of Public Economics 90, 513-531.

[6] FitzGerald, V., 2004. Global Financial Information, Compliance, Incentives and Terrorist Funding. European Journal of Political Economy 20, 387-40. 
[7] International Monetary Fund, 2004. The IMF and the Fight against Money Laundering and the Financing of Terrorism, A Fact sheet.

[8] Kanbur, R., Keen M.J., 1993. Jeux Sans Frontières: Tax Competition and Tax Coordination When Countries differ in Size. American Economic Review 83, 877-892.

[9] Levi, M., 2002. Money laundering and its regulation. Annals of the American Academy of Political and Social Science 582, 181-194.

[10] Masciandaro, D., 2005. False and Reluctant Friends? National Money Laundering Regulation. International Compliance and Non-Cooperative Countries. European Journal of Law and Economics 20, 17-30.

[11] Masciandaro, D., 2006. The International Financial War Against Terrorism: Myths and Reality, in J.Gunning and S. Holm, Ethics, Law and Society, Vol.2, Ashgate, Aldershot, $211-218$.

[12] OCDE, 2010. Promoting Transparency and Exchange of Information for Tax Purposes. Background Briefing. 1-16.

[13] Oral, W.H., Suss, E.C., Mendis, C., 2005. Offshore Financial Centres in the Caribbean: Prospects in a New Environment. World Economy 28, 1173-1188.

[14] Palan, R., 1998. Trying to Have Your Cake and Eating It: How and Why the State System Has Created Offshore, International Studies Quarterly 42, 625-644.

[15] Picard, P.M., and Pieretti P., 2009. Bank Secrecy, Illicit Money and Offshore Financial Centers. Paolo Baffi Centre Research Paper 2009-45.

[16] Rose, A. K., Spiegel, M., 2007. Offshore Financial Centers: Parasites or Symbionts? Economic Journal, 117(523), 1310-1335.

[17] Sharman, J., 2004. International Organisations, Blacklisting and Tax Haven Regulatory Reform. Paper presented at the annual meeting of the International Studies Association, Quebec, Canada Online. 2009-05-26 from http://www.allacademic.com/meta/p73446_index.html. 
[18] Sharman, J., 2006. Norms, coercion and contracting in the struggle against 'harmful' tax competition. Australian Journal of International Affairs, 60(1), 143-169.

[19] Slemrod, J., and Wilson, J., 2009. Tax Competition With Parasitic Tax Havens. Journal of Public Economics, 93(11-12), 1261-1270.

[20] The Economist, 2001. Money Laundering: Fighting the dirt. June 23.

[21] The Economist, 2007. Offshore and Beyond the Pale. February 22.

[22] The Economist, 2007. Survey: Offshore Finance. February 22.

[23] UNDCP World Drug Report, 1997. UNDCP/Oxford University Press.

[24] Williams, O.H., Suss, E.C., Mendis, C., 2005. Offshore Financial Centres in the Caribbean: Prospects in a New Environment. The World Economy, 28(8), 1173-1188.

[25] Wilson, J. D., Wildasin, D., 2004. Capital tax competition: bane or boon. Journal of Public Economics, 88(6), 1065-1091.

\section{Appendix A: Proof of Proposition 3}

We look for the maximum of $\Omega(a), a \in[0, \infty)$, where $\Omega(a)=\Omega^{m}(a)$ if $a \in\left[a_{F}, \infty\right)$ and $\Omega(a)=$ $\Omega^{o}(a, \beta)$ if $a \in\left[0, a_{F}\right)$. Note that $\Omega^{m}(a)$ is decreasing in $a$ so that $\arg \max _{a \in\left[a_{F}, \infty\right)} \Omega^{m}(a)=a_{F}$. Also, because $\Omega^{o}(a, \beta)$ is a convex function of $a\left(a \in\left[0, a_{F}\right)\right)$ we get that $\arg \max _{a \in\left[0, a_{F}\right)} \Omega^{o}(a, \beta)$ $\in\left\{0, a_{F}-\varepsilon\right\}$ where $\varepsilon$ is an infinitely small positive number. Let us define the level $\bar{\gamma}$ such that $\lim _{\varepsilon \rightarrow 0} \Omega^{o}\left(a_{F}-\varepsilon, \beta\right)=\Omega^{o}(0, \beta)$. One readily shows that $\arg \max _{a \in\left[0, a_{F}\right)} \Omega^{o}(a, \beta)$ is equal to $a_{F}-\varepsilon$ if $\gamma<\bar{\gamma}$ and equal to 0 otherwise.

Consider first that $\gamma<\bar{\gamma}$. Then, the optimal pressure is $a^{*}=a_{F}-\varepsilon$ if $\Omega^{o}\left(a_{F}-\varepsilon, \beta\right) \geq \Omega^{m}\left(a_{F}\right)$ and $a^{*}=a_{F}$ otherwise (see Figure 2). This situation arises if and only if $\lim _{\varepsilon \rightarrow 0} T_{H}^{o}\left(a_{F}-\varepsilon\right)-$ $\gamma\left(a_{F}-\varepsilon\right)-\beta(1-\mu) S \geq T_{H}^{m}\left(a_{F}\right)-\gamma a_{F}$; that is, if $\beta \leq \beta_{1} \equiv\left[T_{H}^{o}\left(a_{F}\right)-T_{H}^{m}\left(a_{F}\right)\right] /[(1-\mu) S]$, which simplifies to the expression shown in the text. Accordingly, we get the optimal pressure $a^{*}=a_{F}-\varepsilon$ if $\beta<\beta_{1}$ and $a^{*}=a_{F}$ if $\beta \geq \beta_{1}$. 
Consider secondly that $\gamma>\bar{\gamma}$ so that the optimal pressure is $a^{*}=0$ if $\Omega^{o}(0, \beta) \geq \Omega^{m}\left(a_{F}\right)$ and $a^{*}=a_{F}$ otherwise (see Figure 3 ). That is, if $T_{H}^{o}(0)-\gamma \cdot 0-\beta(1-\mu) S \geq T_{H}^{m}\left(a_{F}\right)-\gamma a_{F}$. This is equivalent to $\beta \leq \beta_{2} \equiv\left[T_{H}^{o}(0)-T_{H}^{m}\left(a_{F}\right)+\gamma a_{F}\right] /[(1-\mu) S]$, which simplifies to the expression shown in the text. Therefore, the pressure policy is $a^{*}=0$ if $\beta<\beta_{2}, a^{*}=a_{F}$ if $\beta>\beta_{2}$. If $\beta=\beta_{2}$, then $a^{*} \in\left\{0, a_{F}\right\}$. Since the latter case has a zero measure in the set of parameters $(\beta, \gamma)$, we omit it in the proposition.

\section{Appendix B: Offshore jurisdiction supply}

To support the above analysis, we prove the following propositions. We assume that offshore jurisdictions $l=1,2, \ldots, N$ are present in the international financial market. All offshore banks make their monitoring decisions and then governments and financial centers make simultaneous decisions over tax and interest rates. We solve this game by backward induction and derive the sub-game perfect equilibrium of this game.

Proposition 6 In the tax and interest rate sub-game, the offshore financial centers $l=\{1,2, \ldots N\}$ offer net interest rates $r_{l}-t_{l}$ no lower than $r-c$ or $r-a$. Either offshore jurisdictions collect no tax revenues or they share a banking profit that is not larger than $\max \left\{\Pi_{F N}, \bar{\Pi}_{F N}\right\}$ if $c>a$, and $\Pi_{F 1}$ if $c<a$.

Proof: Suppose that financial centers have made their monitoring decisions $s=\left(s_{1}, \ldots, s_{N}\right)$ where $s_{l} \in\{m, o\}$. We first analyze the tax and interest rate decisions of offshore institutions. For a set of monitoring decisions $s$, both offshore governments and financial centers play a Bertrand competition game in terms of tax and interest rates. On the one hand, for a given set of tax rates $t^{*}=\left(t_{1}^{*}, \ldots, t_{N}^{*}\right)$, the offshore center $l$ attracts the onshore ordinary investors only if it can offer the highest return net of tax or reputation loss; that is, either $r_{l}-t_{l}^{*}$ when it monitors or $r_{l}-t_{l}^{*}-a$ when it is lax. Each offshore financial center overbids the interest rate of other offshore centers in order to become more attractive and reap the full demand of international investors. Lax financial centers are able raise their interest rates up to $r$ whereas monitoring centers are able to raise them only up to $r-c$ without making a loss. On the other hand, for a given set of interest rates $r^{*}=\left(r_{1}^{*}, \ldots, r_{N}^{*}\right)$, offshore jurisdictions are also enticed 
to attract investors by diminishing their tax rates. Each offshore government has incentives to undercut its rival until its tax rate falls to zero. Let us denote the net return offered by the most attractive offshore financial center by $n_{F} \equiv r_{F}-t_{F}-\alpha_{F} \equiv \min _{l}\left(r_{l}-t_{l}-\alpha_{l}\right)$ where $\alpha_{l}=0$ if $l$ is monitoring and $\alpha_{l}=a$ if $l$ is lax.

Second, the onshore institutions set their optimal interest and tax rates given the offshore institutions' decisions. The best response functions of the onshore jurisdiction and financial center, $r_{H}^{*}=\arg \max _{r_{H}} \Pi\left(r_{H}, r^{*} ; t_{H}, t^{*}\right)$ and $t_{H}^{*}=\arg \max _{t_{H}} T\left(r_{H}, r^{*} ; t_{H}, t^{*}\right)$, are computed as $\widetilde{r}_{H}\left(r ; t_{H}, t\right)=\frac{1}{2}\left(r-c-k+t_{H}+n_{F}\right)$ and $\widetilde{t}_{H}\left(r_{H}, r ; t\right)=\frac{1}{2}\left(k+r_{H}-n_{F}\right)$ where $n_{F}=r_{F}-t_{F}-$ $\alpha_{F}$ is the net return of the most attractive offshore financial center. Solving this system of two identities w.r.t. $r_{H}$ and $t_{H}$, we get the (joint) best response of the onshore jurisdiction and financial center as the following functions of $n_{F}: \widetilde{r}_{H}\left(n_{F}\right)=\frac{1}{3}\left[2 r-2 c-k+n_{F}\right]$ and $\widetilde{t}_{H}\left(n_{F}\right)=$ $\frac{1}{3}\left[r-c+k-n_{F}\right]$. The onshore financial center and jurisdiction offer a net interest rate (net of tax and reputation harm) to investors that is equal to $\widetilde{n}_{H}\left(n_{F}\right)=\widetilde{r}_{H}\left(n_{F}\right)-\widetilde{t}_{H}\left(n_{F}\right)=$ $\frac{1}{3}(r-c-2 k)+\frac{2}{3} n_{F}$. The onshore profit and tax revenues are then equal to $\widetilde{\Pi}_{H}\left(n_{F}\right)=\widetilde{T}_{H}\left(n_{F}\right)$ $=\frac{\mu}{9 k} S\left(c-k-r+n_{F}\right)^{2}$.

We are now equipped to derive and discuss the interest and tax sub-game equilibrium. First, if all offshore centers monitor, $s=(m, \ldots, m)$, all offshore jurisdictions and financial centers offer their maximal interest rate $r-c$ and set their taxes to zero. The onshore jurisdiction and financial center set a net interest rate equal to $\tilde{n}_{H}(r-c)$ and makes profits and tax revenues equal to $\widetilde{\Pi}_{H}(r-c)=\widetilde{T}_{H}(r-c)=\frac{1}{9} k \mu S$. The international financial market offers no profits and no tax revenues for offshore banks and jurisdictions. Second, if all offshore centers do not monitor, $s=(o, \ldots, o)$, all offshore jurisdictions and financial centers offer the maximal interest rate $r$ and also set their taxes to zero. The onshore financial center sets a net interest rate offered equal to $\widetilde{n}_{H}(r-a)$. The onshore profit and tax revenues are equal to $\widetilde{\Pi}_{H}(r-a)=\widetilde{T}_{H}(r-a)=\frac{1}{9 k} \mu S(a-c+k)^{2}$ if $a-c>-k$ and zero otherwise. Third, if more than one center choose to monitor and more than one center choose not to monitor, $s=(m, \ldots, m, o, \ldots, o)$, all offshore jurisdictions offer their maximal interest rate $r$ or $r-c$ and also set their taxes to zero. If $c<a$, international investors deposit their funds at the rate $r-c$ in the centers that monitor. Onshore profits and tax revenues are equal to $\widetilde{\Pi}_{H}(r-c)$ 
and $\widetilde{T}_{H}(r-c)$. Otherwise, they deposit at the rate $r-a$ in the lax centers. Onshore profits and tax revenues are equal to $\widetilde{\Pi}_{H}(r-a)$ and $\widetilde{T}_{H}(r-a)$. Because of competition within each group of offshore monitoring and lax centers, no center makes a profit and no jurisdiction gets tax revenues.

Fourth, if all but one jurisdictions adopt a lax behavior, $s=(m, o, \ldots, o)$, then the lax jurisdictions and financial centers offer their maximal interest rate $r$ and set their taxes to zero. If $c>a$, the monitoring jurisdiction is unable to compete with the lax jurisdictions even if it sets its maximal interest rate $r-c$ and its tax to zero. Profits and tax revenues are then nil in all offshore jurisdictions. Onshore profits and tax revenues are equal to $\widetilde{\Pi}_{H}(r-a)$ and $\widetilde{T}_{H}(r-a)$. Otherwise, if $c<a$, the monitoring jurisdiction ( $\operatorname{say} l=1$ ) is able to undercut the lax centers and to offer an net return equal to $r-a$. The onshore profits and tax revenues are equal to $\widetilde{\Pi}_{H}(r-a)$ and $\widetilde{T}_{H}(r-a)$. The government and the banks of this monitoring offshore jurisdiction 1 then share the value of $\Pi_{F 1}=(a-c)\left[(r-a)-\widetilde{n}_{H}(r-a)\right] \frac{\mu S}{k}=(a-c)(2 k-a+c) \frac{\mu S}{3 k}$.

Finally, if all but one jurisdiction monitors, $s=(m, \ldots, m, o)$, then the monitoring jurisdictions and centers offer their maximal interest rate $r-c$. If $c<a$, the lax jurisdiction and financial center are unable to compete for ordinary investors with the monitoring jurisdictions even if it sets its maximal interest rate $r$ and its tax to zero. The lax jurisdiction ( say $l=N$ ) then targets only the criminal investors so that its banking sector and its government share the surplus obtained from those investors $\Pi_{F N}=r(1-\mu) S$. By contrast, the financial centers and governments of monitoring jurisdictions make no profits and no tax revenues. Onshore profits and tax revenues are equal to $\widetilde{\Pi}_{H}(r-c)$ and $\widetilde{T}_{H}(r-c)$. Otherwise, if $c>a$, the lax jurisdiction can compete with the monitoring jurisdictions by offering a net return equal to $r-c$. If the reputation harm $a$ and the number of criminal investors $1-\mu$ are not too high, this strategy gives a profit higher than targeting only criminal investors. This occurs if $\Pi_{F N}=r(1-\mu) S$ is smaller than $\bar{\Pi}_{F N}=(c-a)\left\{(1-\mu) S+\mu \frac{1}{k}\left[r-c-\widetilde{n}_{H}(r-c-a)\right] S\right\}=$ $(c-a)[(3-\mu) k+2 a \mu] \frac{1}{3 k} S$. In any configuration, the maximal profit that a jurisdiction can obtain is equal to $\max \left\{\Pi_{F N}, \bar{\Pi}_{F N}\right\}$ if $c>a$, and $\Pi_{F 1}$ if $c<a$.

We can now turn to the offshore banks' monitoring decisions $s=\left(s_{1}, \ldots, s_{N}\right)$.

Proposition 7 All monitoring configurations are Nash equilibria except the configuration where 
all offshore financial centers monitor if $c<a$ and the configuration where all offshore financial centers do not monitor if $c>a$.

Proof: We first prove that if $c>a$, all monitoring decisions except $s=(m, \ldots, m)$ are Nash equilibria. On the one hand, the configuration $s=(m, \ldots, m)$ is not an equilibrium because any single monitoring financial center can get a share of the positive profit $\max \left\{\Pi_{F N}, \bar{\Pi}_{F N}\right\}$ by deviating and choosing a lax behavior. On the other hand any configuration $s=(m, \ldots, m, o)$ is an equilibrium. Indeed, a monitoring financial center cannot increase its profit by choosing a lax behavior because this induces competition with the lax center. Also, the lax center cannot increase its profit by deciding to monitor as this decision makes it face the competition with the existing monitoring centers. The same argument applies for the configurations $(m, \ldots, m, o, \ldots, o)$ and $(m, o, \ldots, o)$. We secondly prove that if $c<a$, all monitoring decisions except $s=(o, \ldots, o)$ are Nash equilibria. Indeed, on the one hand, the configuration $s=(o, \ldots, o)$ is not an equilibrium because any single lax financial center can get a share of the positive profit $\Pi_{F 1}$ by deviating and choosing a monitoring behavior. On the other hand, the configurations $s=(m, \ldots, m, o),(m, \ldots, m, o, \ldots, o)$ and $(m, o, \ldots, o)$ are also equilibria as no deviations yield a positive profit due to the competition with other offshore centers.

\section{Appendix C: Offshore jurisdiction size}

Let $L_{F}$ define the mass of offshore local investors and let $l_{F}=L_{F} /(\mu S)$ define its share in the total population (i.e. $L_{F} \equiv \mu S l_{F}$ ). To encompass both monitoring and lax behavior we define $\left(\alpha_{F}, c_{F}, \nu_{F}\right)=(0, c, 0)$ if the offshore bank $F$ monitors $\left(s_{F}=m\right)$, and $\left(\alpha_{F}, c_{F}, \nu_{F}\right)=(a, 0, \nu)$ if it is $\operatorname{lax}\left(s_{F}=o\right)$ where $\nu \equiv(1-\mu) / \mu$ the relative share of criminal investors. We study the equilibiurm under autarky and no autarky.

No autarky: Suppose that the offshore center attracts ordinary investors. The share of offshore investors is given by $x_{F}=\frac{1}{k}\left(r_{F}-t_{F}-\alpha_{F}-r_{H}+t_{H}\right)$, whereas onshore and offshore investor supplies are equal to $D_{H}=\mu S x_{H}$ and $D_{F}=\mu S\left(x_{F}+l_{F}+\nu_{F}\right)$. Profits and tax revenues are equal to $\Pi_{H}=D_{H}\left(r-c-r_{H}\right), \Pi_{F}=D_{F}\left(r-c_{F}-r_{F}\right), T_{H}=t_{H} D_{H}$ and $T_{F}=t_{F} D_{F}$. The interior Nash equilibrium is given by $r_{i}^{*}=\arg \max _{r_{i}} \Pi_{i}\left(r_{i}, r_{-i}^{*} ; t^{*}\right)$ and 
$t_{i}^{*}=\arg \max _{t_{i}} T_{i}\left(r^{*} ; t_{i}, t_{-i}^{*}\right) \forall i=H, F$. The best interest rate and tax responses are given by:

$$
\begin{aligned}
\widetilde{r}_{H}\left(r_{F}, t\right) & =\frac{1}{2}\left(r-\alpha_{F}-c-k+r_{F}-t_{F}+t_{H}\right) \\
\widetilde{r}_{F}\left(r_{H}, t\right) & =\frac{1}{2}\left[r+\alpha_{F}-c_{F}-k\left(l_{F}+\nu_{F}\right)+r_{H}+t_{F}-t_{H}\right] \\
\widetilde{t}_{H}\left(r, t_{F}\right) & =\frac{1}{2}\left(k+r_{H}-r_{F}+\alpha_{F}+t_{F}\right) \\
\widetilde{t}_{F}\left(r, t_{H}\right) & =\frac{1}{2}\left[k\left(l_{F}+\nu_{F}\right)+r_{F}-r_{H}-\alpha_{F}+t_{H}\right]
\end{aligned}
$$

One computes the no-autarky Nash equilibrium as

$$
\begin{aligned}
r_{H}^{*} & =r-\frac{1}{5}\left[4 c+\alpha_{F}+c_{F}+k\left(3+2\left(\nu_{F}+l_{F}\right)\right)\right] \\
r_{F}^{*} & =r-\frac{1}{5}\left[c-\alpha_{F}+4 c_{F}+k\left(2+3\left(\nu_{F}+l_{F}\right)\right)\right] \\
t_{H}^{*} & =\frac{1}{5}\left[k\left(3+2\left(\nu_{F}+l_{F}\right)\right)+\alpha_{F}-c+c_{F}\right] \\
t_{F}^{*} & =\frac{1}{5}\left[k\left(2+3\left(\nu_{F}+l_{F}\right)\right)-\alpha_{F}+c-c_{F}\right]
\end{aligned}
$$

Investors' supplies are given by

$$
\begin{aligned}
D_{H}^{*} & =\frac{\mu S}{5 k}\left[k\left(3+2\left(\nu_{F}+l_{F}\right)\right)+\alpha_{F}-c+c_{F}\right] \\
D_{F}^{*} & =\frac{\mu S}{5 k}\left[k\left(2+3\left(\nu_{F}+l_{F}\right)\right)-\alpha_{F}+c-c_{F}\right]
\end{aligned}
$$

Profits and tax revenues are given by $\Pi_{i}^{*}=T_{i}^{*}=\frac{k}{\mu S}\left(D_{i}^{*}\right)^{2}$.

In this no-autarky equilibrium, the offshore bank decides to monitor if its profit $\Pi_{F}$ is greater under monitoring than lax behavior. Using the above values, one gets the condition $a>a_{F}=c+3 k \nu$, which is independent of $l_{F}$. At this value there exists a jump in the welfare objective of a central planner so that Proposition 1 applies. Under a lax behavior where $a<a_{F}$, $T_{F}^{*}$ is again a convex, increasing function of $a$, which implies that Proposition 3 applies.

To be a no-autarky equilibrium, this equibrium must additionally yield higher profits and tax revenues than the profits and tax revenues obtained when offshore financial center and government target their local investors. We now consider possible deviation of the offshore 
center towards autarky. Let us consider an offshore center with interest and tax rates $\left(r_{F}^{*}, t_{F}^{*}\right)$. On the one hand, suppose that the offshore financial center reduces its interest rate and its net return so that it foregoes the international investors. towards this aim, it sets the lowest possible interest rate $r_{F}=t_{F}^{*}$. This action decreases its profit by an amount equal to

$$
\begin{aligned}
\Pi_{F}^{*}-\Pi_{F}= & \mu S\left[\left(l_{F}+\nu_{F}\right)+\frac{1}{k}\left(r_{F}^{*}-t_{F}^{*}-\alpha_{F}-r_{H}^{*}+t_{H}^{*}\right)\right]\left(r-c_{F}-r_{F}^{*}\right) \\
& -\mu S\left(l_{F}+\nu_{F}\right)\left(r-c_{F}-t_{F}^{*}\right)
\end{aligned}
$$

which is positive if $24 k^{2}\left(\nu_{F}+l_{F}\right)^{2}-\left(\nu_{F}+l_{F}\right) k\left(25 r-11 c-22 k+11 \alpha_{F}-14 c_{F}\right)+\left(c+2 k-\alpha_{F}-c_{F}\right)^{2}$ $>0$. A sufficient condition is that

$l_{F}<l_{F}^{1}=\frac{\left(c+2 k-\alpha_{F}-c_{F}\right)^{2}}{k\left(25 r-11 c-22 k+11 \alpha_{F}-14 c_{F}\right)}-\nu_{F}=\left\{\begin{array}{cc}\frac{(2 k)^{2}}{k(25 r+3 c-22 k)} & \text { if monitoring } \\ \frac{(2 k+c-a)^{2}}{k(25 r-22 k+11(a-c))}-\frac{1-\mu}{\mu} & \text { if lax }\end{array}\right.$

On the other hand, suppose that the offshore government increases its tax and and reduces the net return in its jurisdiction so that it also foregoes the international investors. towards this aim, it sets the highest possible tax $t_{F}=r_{F}^{*}$. This action also decreases its tax revenues by an amount equal to

$$
\begin{aligned}
T_{F}^{*}-T_{F}= & \mu S\left[\left(l_{F}+\nu_{F}\right)+\frac{1}{k}\left(r_{F}^{*}-t_{F}^{*}-\alpha_{F}-r_{H}^{*}+t_{H}^{*}\right)\right] t_{F}^{*} \\
& -\mu S\left(l_{F}+\nu_{F}\right) r_{F}^{*}
\end{aligned}
$$

Because $r_{F}^{*}+t_{F}^{*}=r-c_{F}$, this condition is equivalent to condition (7). A sufficient condition is also $l_{F}<l_{F}^{1}$. Therefore, there is a no-autarky equilibrium if $l_{F} \leq l_{F}^{1}$.

Autarky: We here characterize the interest and tax rates in this autarkic equilibrium and the conditions under which it occurs. Suppose that the offshore jurisdiction chooses autarky by targeting only their own local investors. Under autarky, the offshore financial center gets a profit given by $\Pi_{F}^{A}=\max _{r_{F}} \mu S\left(l_{F}+\nu_{F}\right)\left(r-c_{F}-r_{F}\right)$ subject to the local investors' participation $r_{F}-t_{F}^{A} \geq 0$, while the offshore government gets a reservation tax revenue given by $T_{F}^{A}=\max _{t_{F}} \mu S\left(l_{F}+\nu_{F}\right) t_{F}$ subject to $r_{F}^{A}-t_{F} \geq 0$. In those expressions, the superscript $A$ stands for the autarkic equilibrium. We compute that $\Pi_{F}^{A}=\mu S\left(l_{F}+\nu_{F}\right)\left(r-c_{F}-t_{F}^{A}\right)$ 
and $T_{F}^{A}=\mu S\left(l_{F}+\nu_{F}\right) r_{F}^{A}$ while $r_{F}^{A}-t_{F}^{A}=0$. This yields $r_{F}^{A}=t_{F}^{A} \in\left[0, r-c_{F}\right]$ and $T_{F}^{A}+\Pi_{F}^{A}=\mu S\left(l_{F}+\nu_{F}\right)\left(r-c_{F}\right)$. The same analysis occurs in the onshore jurisdiction: $r_{H}^{A}=t_{H}^{A} \in[0, r-c]$ and $T_{H}^{A}+\Pi_{H}^{A}=\mu S(r-c)$. The investor's net return (net of tax and reputation harm) are nil in both jurisdictions.

Let us consider an offshore center with interest and tax rates $r_{F}^{A}=t_{F}^{A}$. The offshore financial center prefers to not raise its interest rate $r_{F}$ and its net return to attract onshore investors because the profit differential

$$
\Pi_{F}-\Pi_{F}^{A}=\mu S\left[\left(l_{F}+\nu_{F}\right)+\frac{1}{k}\left(r_{F}-r_{F}^{A}-\alpha_{F}^{A}\right)\right]\left(r-c_{F}^{A}-r_{F}\right)-\mu S\left(l_{F}+\nu_{F}\right)\left(r-c_{F}-t_{F}^{A}\right)
$$

decreases in $r_{F}$ from a non positive value at $r_{F}=r_{F}^{A}$ if $l_{F}+\nu_{F} \geq \frac{1}{k}\left(r+\alpha_{F}^{A}-c_{F}^{A}+t_{F}^{A}-2 r_{F}\right)$. A sufficient condition is obtained by setting $r_{F}$ to its minimal value $t_{F}^{A}$ and setting $t_{F}^{A}$ to its minimal value 0 . So, we get $l_{F}+\nu_{F} \geq \frac{1}{k}\left(r+\alpha_{F}^{A}-c_{F}^{A}\right)$, or equivalently

$$
l_{F}>l_{F}^{2} \equiv \frac{1}{k}\left(r+\alpha_{F}^{A}-c_{F}^{A}\right)-\nu_{F}=\left\{\begin{array}{cc}
\frac{1}{k}(r-c) & \text { if monitoring center } \\
\frac{1}{k}(r+a)-\frac{1-\mu}{\mu} & \text { if lax center }
\end{array}\right.
$$

Similarly, the government prefers to not reduce its tax $t_{F}$ and and not to raise its net return to attract onshore investors because the tax revenue differential

$$
T_{F}-T_{F}^{A}=\mu S\left[l_{F}+\nu_{F}+\frac{1}{k}\left(r_{F}^{A}-t_{F}-\alpha_{F}^{A}\right)\right] t_{F}-\mu S\left(l_{F}+\nu_{F}\right) t_{F}^{A}
$$

is always negative for $t_{F}<t_{F}^{A}=r_{F}^{A}$. Indeed, this expression has a non positive value at $t_{F}=t_{F}^{A}$ and decreases with smaller $t_{F}$ if $l_{F}+\nu_{F}+\frac{1}{k}\left(r_{F}^{A}-2 t_{F}-\alpha_{F}^{A}\right) \geq 0$. A sufficient condition for the latter condition is obtained by setting $t_{F}$ to its maximal value $r_{F}^{A}$ and setting $r_{F}^{A}$ to its maximal value $r-c_{F}$. So, we obtain $l_{F}+\nu_{F}+\frac{1}{k}\left(r-c_{F}-\alpha_{F}^{A}\right) \geq 0$, which is satisfied given Condition (1). 


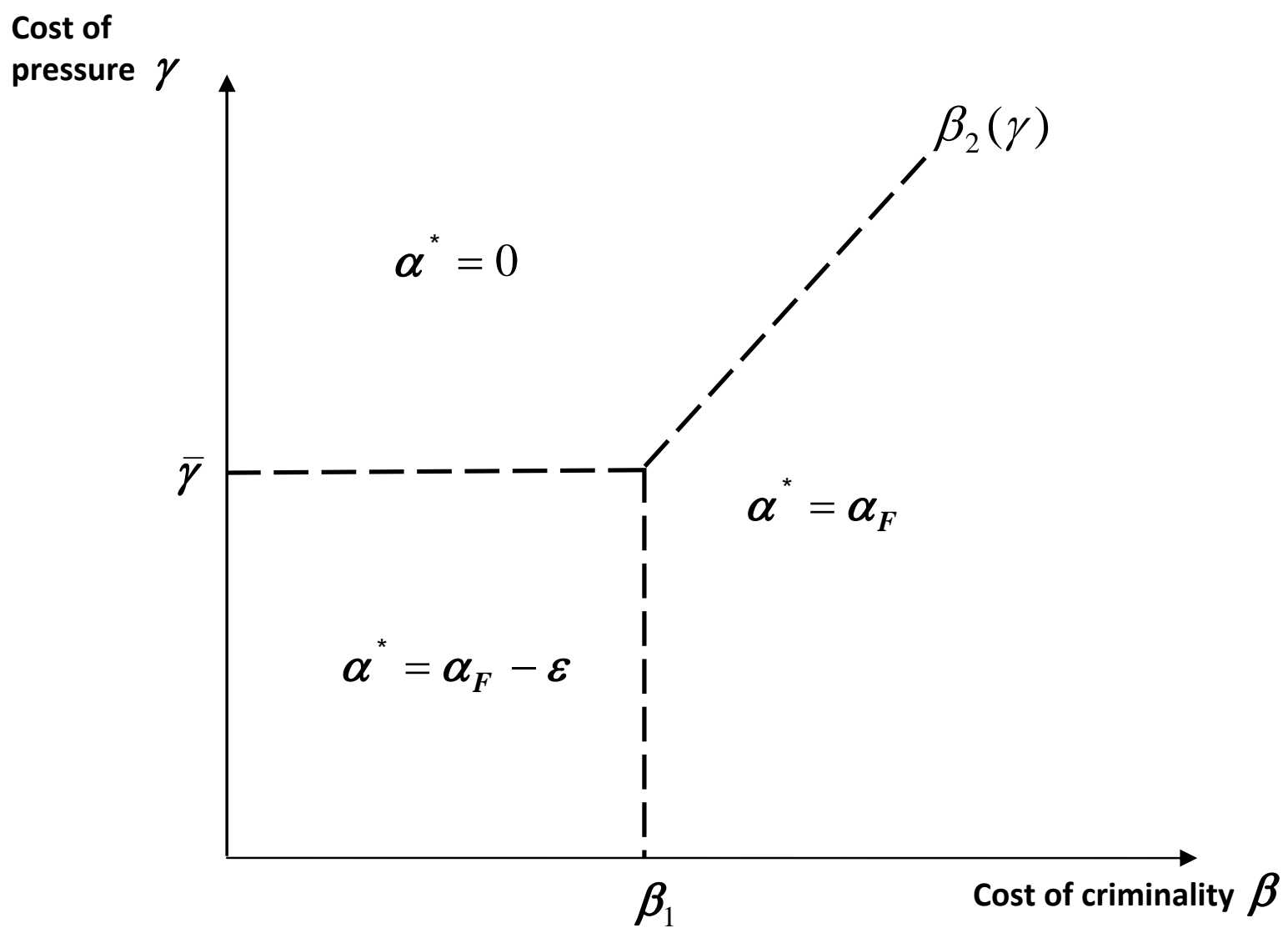

Figure 1: Pressure policy under delegation to onshore agency 


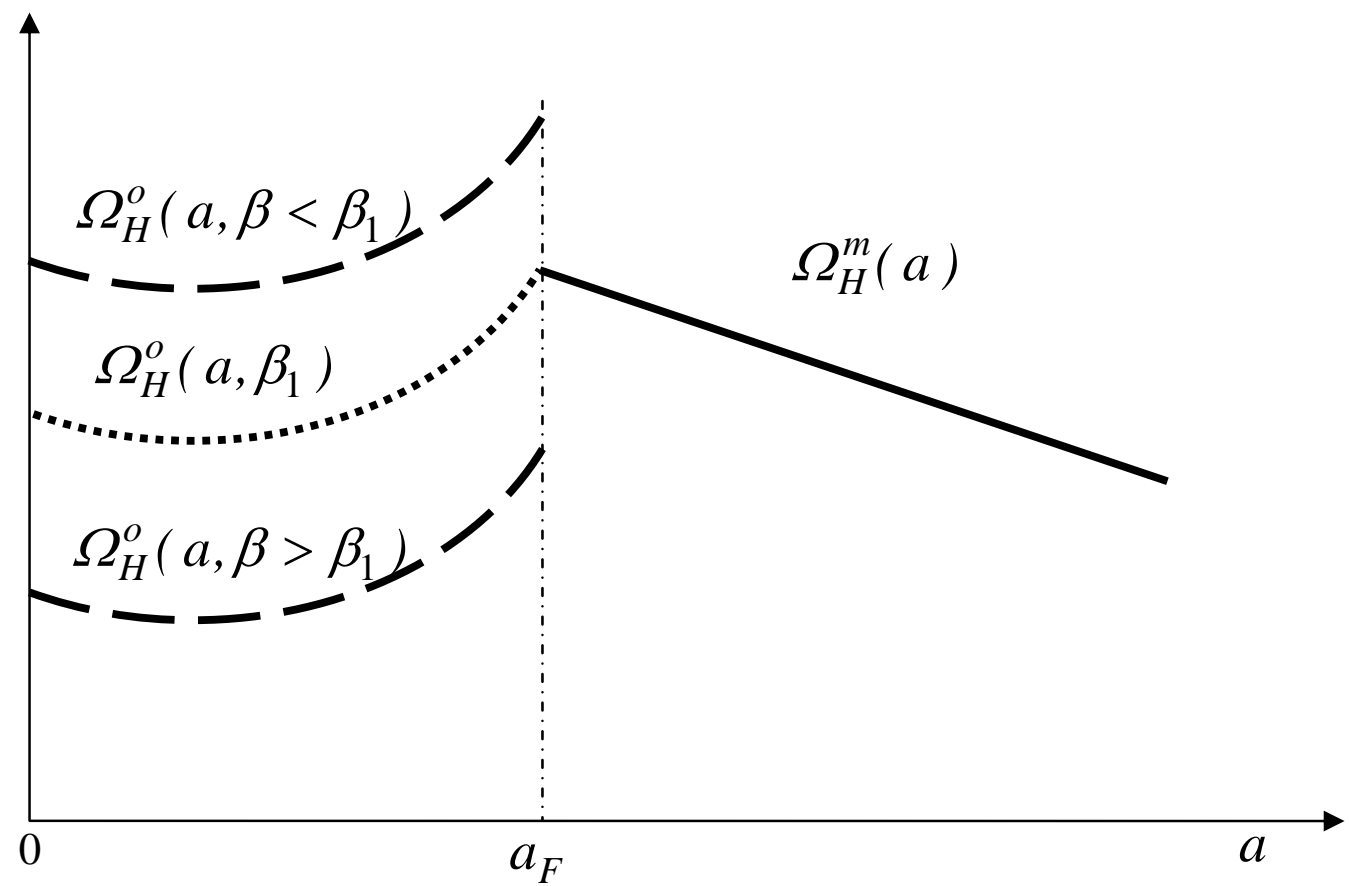

Figure 2: Objective function of onshore agency under delegation $(\gamma<\bar{\gamma})$

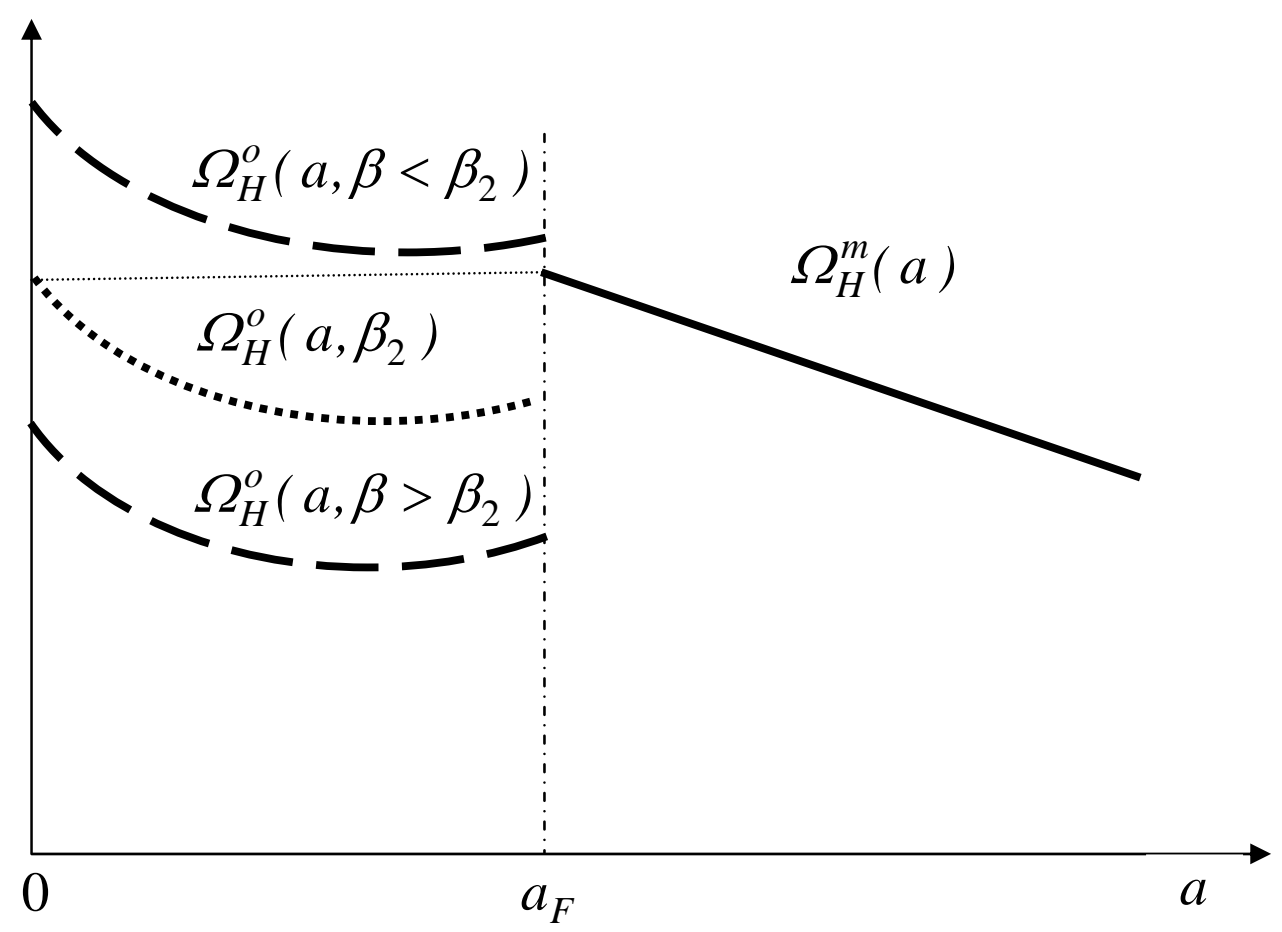

Figure 3: Objective function of onshore agency under delegation $(\gamma>\bar{\gamma})$ 


\section{Recent titles \\ CORE Discussion Papers}

2009/65. David DE LA CROIX and Clara DELAVALLADE. Why corrupt governments may receive more foreign aid.

2009/66. Gilles GRANDJEAN, Ana MAULEON and Vincent VANNETELBOSCH. Strongly rational sets for normal-form games.

2009/67. Kristian BEHRENS, Susana PERALTA and Pierre M. PICARD. Transfer pricing rules, OECD guidelines, and market distortions.

2009/68. Marco MARINUCCI and Wouter VERGOTE. Endogenous network formation in patent contests and its role as a barrier to entry.

2009/69. Andréas HEINEN and Alfonso VALDESOGO. Asymmetric CAPM dependence for large dimensions: the Canonical Vine Autoregressive Model.

2009/70. Skerdilajda ZANAJ. Product differentiation and vertical integration in presence of double marginalization.

2009/71. Marie-Louise LEROUX and Grégory PONTHIERE. Wives, husbands and wheelchairs: Optimal tax policy under gender-specific health.

2009/72. Yu. NESTEROV and Levent TUNCEL. Local quadratic convergence of polynomial-time interior-point methods for conic optimization problems.

2009/73. Grégory VANDENBULCKE, Claire DUJARDIN, Isabelle THOMAS, Bas DE GEUS, Bart DEGRAEUWE, Romain MEEUSEN and Luc INT PANIS. Cycle commuting in Belgium: Spatial determinants and 're-cycling' strategies.

2009/74. Noël BONNEUIL and Raouf BOUCEKKINE. Sustainability, optimality, and viability in the Ramsey model.

2009/75. Eric TOULEMONDE. The principle of mutual recognition - A source of divergence?

2009/76. David DE LA CROIX, Pierre PESTIEAU and Grégory PONTHIÈRE. How powerful is demography? The Serendipity Theorem revisited.

2009/77. Nicola ACOCELLA, Giovanni DI BARTOLOMEO, Andrew HUGUES HALLETT and Paolo G. PIACQUADIO. Announcement wars as an equilibrium selection device.

2009/78. Julio DÁVILA. The taxation of savings in overlapping generations economies with unbacked risky assets.

2009/79. Elena DEL REY and Miguel Angel LOPEZ-GARCIA. Optimal education and pensions in an endogenous growth model.

2009/80. Hiroshi UNO. Strategic complementarities and nested potential games.

2009/81. Xavier WAUTHY. Market coverage and the nature of product differentiation: a note.

2009/82. Filippo L. CALCIANO. Nash equilibria of games with increasing best replies.

2009/83. Jacques H. DRÈZE, Oussama LACHIRI and Enrico MINELLI. Stock prices, anticipations and investment in general equilibrium.

2009/84. Claire DUJARDIN and Florence GOFFETTE-NAGOT. Neighborhood effect on unemployment? A test à la Altonji.

2009/85. Erwin OOGHE and Erik SCHOKKAERT. School accountability: (how) can we reward schools and avoid cream-skimming.

2009/86. Ilke VAN BEVEREN and Hylke VANDENBUSSCHE. Product and process innovation and the decision to export: firm-level evidence for Belgium.

2010/1. Giorgia OGGIONI and Yves SMEERS. Degree of coordination in market-coupling and counter-trading.

2010/2. Yu. NESTEROV. Efficiency of coordinate descent methods on huge-scale optimization problems.

2010/3. Geert DHAENE an Koen JOCHMANS. Split-panel jackknife estimation of fixed-effect models.

2010/4. Parkash CHANDER. Cores of games with positive externalities.

2010/5. Gauthier DE MAERE D'AERTRYCKE and Yves SMEERS. Liquidity risks on power exchanges.

2010/6. Marc FLEURBAEY, Stéphane LUCHINI, Christophe MULLER and Erik SCHOKKAERT. Equivalent income and the economic evaluation of health care. 


\section{Recent titles}

\section{CORE Discussion Papers - continued}

2010/7. Elena IÑARA, Conchi LARREA and Elena MOLIS. The stability of the roommate problem revisited.

2010/8. Philippe CHEVALIER, Isabelle THOMAS and David GERAETS, Els GOETGHEBEUR, Olivier JANSSENS, Dominique PEETERS and Frank PLASTRIA. Locating fire-stations: an integrated approach for Belgium.

2010/9. Jean-Charles LANGE and Pierre SEMAL. Design of a network of reusable logistic containers.

2010/10. Hiroshi UNO. Nested potentials and robust equilibria.

2010/11. Elena MOLIS and Róbert F. VESZTEG. Experimental results on the roommate problem.

2010/12. Koen DECANCQ. Copula-based orderings of multivariate dependence.

2010/13. Tom TRUYTS. Signaling and indirect taxation.

2010/14. Asel ISAKOVA. Currency substitution in the economies of Central Asia: How much does it cost?

2010/15. Emanuele FORLANI. Irish firms' productivity and imported inputs.

2010/16. Thierry BRECHET, Carmen CAMACHO and Vladimir M. VELIOV. Model predictive control, the economy, and the issue of global warming.

2010/17. Thierry BRECHET, Tsvetomir TSACHEV and Vladimir M. VELIOV. Markets for emission permits with free endowment: a vintage capital analysis.

2010/18. Pierre M. PICARD and Patrice PIERETTI. Bank secrecy, illicit money and offshore financial centers.

\section{Books}

J. GABSZEWICZ (ed.) (2006), La différenciation des produits. Paris, La découverte.

L. BAUWENS, W. POHLMEIER and D. VEREDAS (eds.) (2008), High frequency financial econometrics: recent developments. Heidelberg, Physica-Verlag.

P. VAN HENTENRYCKE and L. WOLSEY (eds.) (2007), Integration of AI and OR techniques in constraint programming for combinatorial optimization problems. Berlin, Springer.

P-P. COMBES, Th. MAYER and J-F. THISSE (eds.) (2008), Economic geography: the integration of regions and nations. Princeton, Princeton University Press.

J. HINDRIKS (ed.) (2008), Au-delà de Copernic: de la confusion au consensus ? Brussels, Academic and Scientific Publishers.

J-M. HURIOT and J-F. THISSE (eds) (2009), Economics of cities. Cambridge, Cambridge University Press.

P. BELLEFLAMME and M. PEITZ (eds) (2010), Industrial organization: markets and strategies. Cambridge University Press.

M. JUNGER, Th. LIEBLING, D. NADDEF, G. NEMHAUSER, W. PULlEYBLANK, G. REINELT, G. RINALDI and L. WOLSEY (eds) (2010), 50 years of integer programming, 1958-2008: from the early years to the state-of-the-art. Berlin Springer.

\section{CORE Lecture Series}

C. GOURIÉROUX and A. MONFORT (1995), Simulation Based Econometric Methods.

A. RUBINSTEIN (1996), Lectures on Modeling Bounded Rationality.

J. RENEGAR (1999), A Mathematical View of Interior-Point Methods in Convex Optimization.

B.D. BERNHEIM and M.D. WHINSTON (1999), Anticompetitive Exclusion and Foreclosure Through Vertical Agreements.

D. BIENSTOCK (2001), Potential function methods for approximately solving linear programming problems: theory and practice.

R. AMIR (2002), Supermodularity and complementarity in economics.

R. WEISMANTEL (2006), Lectures on mixed nonlinear programming. 